\title{
Mesoscale ionospheric electrodynamics of omega bands determined from ground-based electromagnetic and satellite optical observations
}

\author{
O. Amm ${ }^{1}$, A. Aksnes ${ }^{2}$, J. Stadsnes ${ }^{2}$, N. Østgaard ${ }^{2,3}$, R.R. Vondrak ${ }^{4}$, G.A. Germany ${ }^{5}$, G.Lu ${ }^{6}$, and A. Viljanen ${ }^{1}$ \\ ${ }^{1}$ Finnish Meteorological Institute, Geophysical Research, P.O. Box 503, FIN-00101 Helsinki, Finland \\ ${ }^{2}$ Department of Physics and Technology, University of Bergen, Bergen, Norway \\ ${ }^{3}$ University of California, Berkeley, CA 94720-7450, USA \\ ${ }^{4}$ NASA/Goddard Space Flight Center, Greenbelt, MD 20771, USA \\ ${ }^{5}$ University of Alabama in Huntsville, AL 35899, USA \\ ${ }^{6} \mathrm{HAO} / \mathrm{NCAR}$, P.O. Box 3000, Boulder, CO 80301-3000, USA
}

Received: 15 March 2004 - Revised: 4 October 2004 - Accepted: 12 October 2004 - Published: 28 February 2005

\begin{abstract}
We present ground-based electromagnetic data from the MIRACLE and BEAR networks and satellite optical observations from the UVI and PIXIE instruments on the Polar satellite of an omega band event over Northern Scandinavia on 26 June 1998, which occured close to the morning side edge of a substorm auroral bulge. Our analysis of the data concentrates on one omega band period from 03:1803:27 UT, for which we use the method of characteristics combined with an analysis of the UVI and PIXIE data to derive a time series of instantaneous, solely data-based distributions of the mesoscale ionospheric electrodynamic parameters with a 1-min time resolution. In addition, the AMIE method is used to derive global Hall conductance patterns. Our results show that zonally alternating regions of enhanced ionospheric conductances ("tongues") up to $\sim 60 \mathrm{~S}$ and low conductance regions are associated with the omega bands. The tongues have a poleward extension of $\sim 400 \mathrm{~km}$ from their base and a zonal extension of $\sim 380 \mathrm{~km}$. While they are moving coherently eastward with a velocity of $\sim 770 \mathrm{~ms}^{-1}$, the structures are not strictly stationary. The current system of the omega band can be described as a superposition of two parts: one consists of anticlockwise rotating Hall currents around the tongues, along with Pedersen currents, with a negative divergence in their centers. The sign of this system is reversing in the low conductance areas. It causes the characteristic ground magnetic signature. The second part consists of zonally aligned current wedges of westward flowing Hall currents and is mostly magnetically invisible below the ionosphere. This system dominates the field-aligned current (FAC) pattern and causes alternating upward and downward FAC at the flanks of the tongues with maximum upward FAC of $\sim 25 \mu \mathrm{A} \mathrm{m}^{-2}$. The total FAC of $\sim 2 \mathrm{MA}$ are comparable to the ones diverted inside a westward traveling surge.
\end{abstract}

Correspondence to: $\mathrm{O}$. Amm

(olaf.amm@fmi.fi)
Throughout the event, the overwhelming part of the FAC are associated with gradients of the ionospheric conductances, and $66-84 \%$ of the FAC are connected with ionospheric Hall currents.

Key words. Ionosphere (auroral ionosphere; electric fields and currents) - Magnetospheric physics (current systems)

\section{Introduction}

Auroral omega bands are periodic, wave-like undulations of the poleward boundary of the morning side diffuse aurora occurring in the recovery phase of substorms. The name omega bands was originally chosen by Akasofu and Kimball (1964) with respect to the dark areas between the poleward extending auroral waves or tongues, which resemble the form of the inverted capital greek letter $\Omega$. The luminous tongues tend to be narrower and having larger latitudinal extent for more intense substorms, and may occasionally develop into auroral torches which are narrow, finger-like auroral forms that extend several degrees of latitude poleward from the auroral oval (Akasofu, 1974). Inside the tongues, which are primarily deformations of the diffuse auroral boundary, discrete aurora can also be found, especially at the tongues' poleward boundary. Pulsating aurora has been observed inside torches. The typical longitudinal, as well as latitudinal extent of the tongues, amounts to about $400-500 \mathrm{~km}$. Omega bands have been found to grow simultaneously over a longitudinal range of several magnetic local time (MLT) hours, and have also been observed simultaneously in both hemispheres (Mravlag et al., 1991).

The auroral forms are drifting eastward with velocities ranging between 400 and $2000 \mathrm{~m} / \mathrm{s}$, with a tendency of increasing drift speed with time. These velocities have been found to agree closely with the local $\boldsymbol{E} \times \boldsymbol{B}$ vec drift velocity. 
During their eastward drift, the shape of the auroral forms is essentially preserved, thus indicating a mostly stationary structure in the frame of reference comoving with the forms. A ground magnetometer positioned below the periodic, stationary and moving auroral omega bands measures Ps6 pulsations, i.e. magnetic disturbances with periods of 5-40 min, and amplitudes that may vary from 10 to over $1000 \mathrm{nT}$. The causal relation between the auroral and the magnetic phenomena was first pointed out by Saito (1978). The ground magnetic pulsations are most prominent in the magnetic $\mathrm{Y}$ (eastward) component, in which the maxima are more pronounced than the minima. The maxima in $\mathrm{Y}$ occur between respective minima and maxima in the $\mathrm{Z}$ (vertical downward) component related to the same omega band, where the $\mathrm{Z}$ minima are leading the $\mathrm{Y}$ maxima by a phase shift of approximately $90^{\circ}$. In the $\mathrm{X}$ (northward) component, the pulsations are also often visible, but they are typically quite disturbed due to the temporal variation of the substorm electrojet intensity during the recovery phase (e.g. Paschmann et al., 2003, their Fig. 6.23).

To explain the observed ground magnetic variations associated with the omega bands, two basic types of ionospheric current systems have been proposed: The first, here called "system 1", is a north-south oriented Cowling channel in which concentrated horizontal currents are flowing southward (Kawasaki and Rostoker, 1979). They are fed by downward flowing FAC on the poleward side and diverged by upward flowing FAC on the equatorward side of the channel. In this model, the electric field is assumed to be uniform, but the conductances are enhanced inside the Cowling channel. In the alternative model of Gustafsson et al. (1981), here called "system 2", the conductances are assumed to be uniform, but the electric field has a negative divergence in the center of the auroral tongues and a positive one in the dark areas between them. Consequently, the ionospheric Pedersen currents are converging or diverging in the tongues or in the dark areas, respectively, leading to upward FACs inside the tongues and downward FACs in the regions in between. Since for uniform ionospheric conductances the combined magnetic effect of Pedersen currents and FACs is invisible below the ionosphere (e.g. Fukushima, 1976), the ground magnetic effect is completely caused by the Hall currents which are circulating around the centers of the electric field divergences, anticlockwise inside the auroral tongues and clockwise in the dark auroral holes. Both current systems described are assumed to be comoving with the auroral form and have to be regarded as being superposed on the background westward electrojet.

While these initial models were composed from data of single latitudinal chains of magnetometers, later studies using combined two-dimensional data of the Scandinavian Magnetometer Array (SMA; Küppers et al., 1979) and the STARE radar (Greenwald et al., 1978) showed that the conductances are clearly enhanced inside the omega bands with respect to the surrounding regions, and after subtraction of the background field, there is a radial electric field component pointing towards the tongues, thus indicating upward field-aligned currents there (e.g. André and Baumjohann, 1982; Opgenoorth et al., 1983a). These studies used a "trial and error" (see Untiedt and Baumjohann, 1993) technique to modify the ionospheric electrodynamic parameters such that they yield a sufficient correspondence with the measured ground magnetic disturbance. The shortcomings of this technique are that no information regarding the uniqueness of the solution exists, and that it makes it necessary to comprise the information of many time steps into one single, spatially large model distribution for a reference time step, assuming that a stationary omega band structure is moving over the measurement network with a constant velocity. Therefore, the models cannot reflect the temporal evolution of the structures.

Later observations of omega bands using data of the EISCAT incoherent scatter radar (Folkestad et al., 1983) and models composed therefrom, together with magnetometer data showed that the steepness of the conductance gradients has been somewhat underestimated by the models using the "trial and error" method (Buchert et al., 1988, 1990; Lühr and Schlegel, 1994; Amm, 1996). The general geometry of these models is in good accordance with results from numerical and theoretical ionosphere-magnetosphere coupling models (Janhunen and Huuskonen, 1993; Yamamoto et al., 1993, 1997). Their weakness is that the EISCAT radar can observe the ionospheric parameters along a single line during one integration time only, and therefore, like in the case of the "trial and error" models, data from different time steps had to be merged into a single model. Consequently, the full spatiotemporal evolution could not be resolved.

Using a decomposition into the curl-free and divergencefree parts of the model current system, Amm (1996) showed that the main geometry and ground magnetic effect of the omega bands is caused by a system 2-type current configuration, but found a system 1-type northwest-southeast aligned Cowling channel at the western flank of the omega band. While this result agrees with the models of Buchert et al. $(1988,1990)$ (who, however, did not separate the two systems spatially), other studies came to the conclusion that system 2 is dominating (Opgenoorth et al., 1983a; Lühr and Schlegel, 1994; Wild et al., 2000).

In this paper we derive, for the first time, instantaneous distributions of ionospheric conductances, currents, and field-aligned currents in 1-min intervals over a whole period of an omega band, using data from the MIRACLE and BEAR ground-based networks, and the UVI and PIXIE instruments on the Polar satellite (see Sect. 2) for an event on 26 June 1998. The two-dimensional method of characteristics (see Sect. 3) is used to perform the combined data analysis. The resulting time series of spatial distributions of the ionospheric electrodynamic parameters allows us to describe the full spatio-temporal evolution of the omega bands and to discuss important open questions, like the balance and the closure of the field-aligned currents between the tongues and the (optically dark) areas in between them (Sect. 4).

We restrict the discussion of the omega bands in this paper to the mesoscale ionospheric electrodynamics related to 
these structures. We will not deal with, for example, particle signatures or the magnetospheric counterparts and excitation mechanisms of the ionospheric structures. For a recent summary of research related to omega bands which also covers these topics, see Paschmann et al. (2003, their Sect. 6.3).

\section{Instrumentation and observations}

The MIRACLE network of ground-based instruments (Syrjäsuo et al., 1998) consists of the IMAGE magnetometer network, the renewed STARE coherent scatter radar, which measures the ionospheric electric field, and several all-sky cameras which are not used in this study due to the northern summer light conditions. For our event on 26 June 1998, in addition to IMAGE, data of the temporary, but very extended BEAR magnetometer network (Korja et al., 2002) are available. These two networks together provide the most dense coverage of magnetometers that has existed in Northern Scandinavia as yet. Figure 1 shows the coverage of magnetometers (dots) and the field of view of the STARE radar (black frame).

From remote sensing of the UV- and X-ray aurora, the Ultraviolet Imager (UVI) and the Polar Ionospheric X-ray Imaging Experiment (PIXIE) on board the Polar satellite can provide instantaneous global maps of the precipitating electrons.

The UVI instrument measures UV-emissions within the Lyman-Birge-Hopfield (LBH) band (140-180 nm), caused mainly by the precipitating electrons impact on $\mathrm{N}_{2}$. When produced at altitudes below about $150 \mathrm{~km}$, some of the LBH emissions will be absorbed by $\mathrm{O}_{2}$. The amount of absorption is determined by the $\mathrm{O}_{2}$ Schumann-Runge absorption continuum, which peaks at the shorter wavelengths and decreases with longer wavelengths. The LBH emissions are thus divided into two bands: A shorter wavelength region of 140-160 nm denoted LBHS, with significant loss due to $\mathrm{O}_{2}$ absorption, and another region between 160 and $180 \mathrm{~nm}$, LBHL, with less loss. By taking the ratio between the intensities of the two LBH-bands, we can estimate the average precipitating electron energy. As the longest wavelengths are hardly affected by $\mathrm{O}_{2}$ absorption, the LBHL emissions are further directly proportional to the incident auroral electron energy flux. Using UVI measurements, we are thus able to perform a remote diagnostic of the precipitating electrons in the energy range between approximately 0.1 and $20 \mathrm{keV}$. The spatial resolution of the UVI camera is nominally $\sim 40 \mathrm{~km}$ (Torr et al., 1995), but wobbling of the despun platform on the Polar satellite means the spatial resolution is degraded in one direction to $\sim 360 \mathrm{~km}$. For more details, see Germany et al. (1997, 1998a, b).

The PIXIE camera measures bremsstrahlung in the energy range between approximately 2 and $22 \mathrm{keV}$ (Imhof et al., 1995), produced by the interaction between precipitating electrons and the nuclei of atmospheric particles. There exists a well-established relationship between precipitating electrons and the production of X-rays (Evans, 1955). From

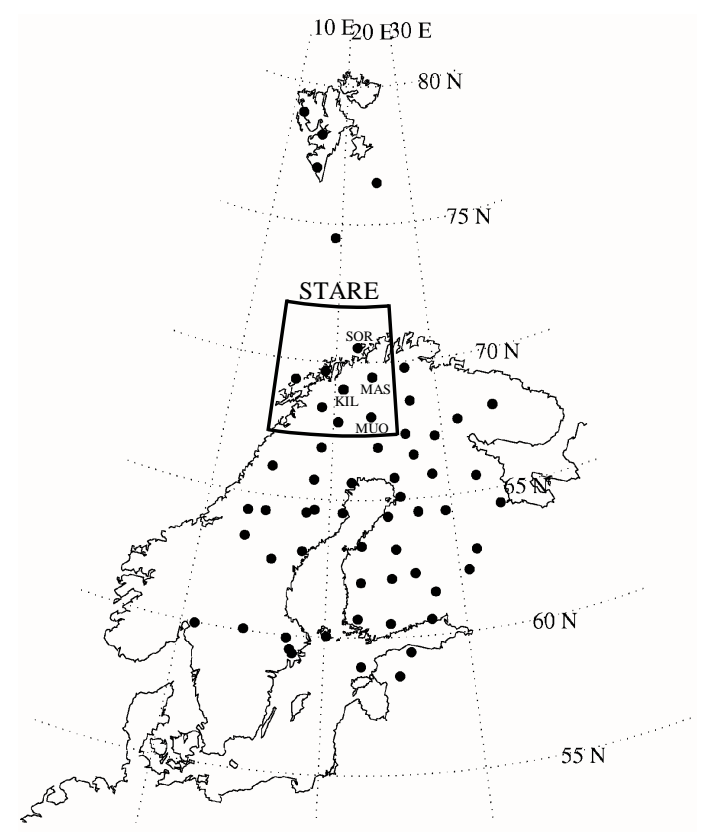

Fig. 1. Location of the IMAGE and BEAR magnetometer stations (dots) in Northern Scandinavia, and the field of view of the STARE radar (black frame).

the derived PIXIE X-ray spectra, a four-parameter representation of the precipitating electron energy spectra can be estimated, having an electron energy range of $5-100 \mathrm{keV}$ and a spatial resolution of $600-900 \mathrm{~km}$ (depending on Polar altitude). A detailed description of the procedure is given by Østgaard et al. (2000, 2001).

The upper panels of Fig. 2 show the $\mathrm{X}$ (northward, left panel) and $\mathrm{Y}$ (eastward, right panel) magnetic disturbance components in a conventional magnetogram representation for three about meridionally aligned magnetometers in the northern mainland of Scandinavia (see Fig. 1), for the whole substorm period during which our event occured. The substorm was detected by the magnetometers at around 01:40 UT, and after a number of intermediate intensifications, the recovery phase lasted at least until $\sim 04: 30$ UT. The ground magnetic disturbance associated with the intense substorm amounts to more than 1000 nT. Between 03:00 UT and 03:30 UT, three omega bands passed over the magnetometers, as indicated by the quasi-periodic pulsations in the $\mathrm{Y}$ component (upper right panel). In order to justify the categorisation of our event as an omega band, in spite of the absence of visual band optical data which were originally used to define these structures, we discuss the magnetometer data of the station Kilpisjärvi (KIL), located quite central in the southern field of view of STARE, in more detail in the lower panel of Fig. 2. Strong Ps6 pulsations can be seen in the $\mathrm{Y}$ magnetic disturbance component, with more pronounced maxima as compared to the minima. Similar pulsations are visible in the $Z$ (vertical downward) component with the minimum in $\mathrm{Z}$ leading the maximum in $\mathrm{Y}$ by about $1 \mathrm{~min}$. Also in the $\mathrm{X}$ component some pulsations are visible, 


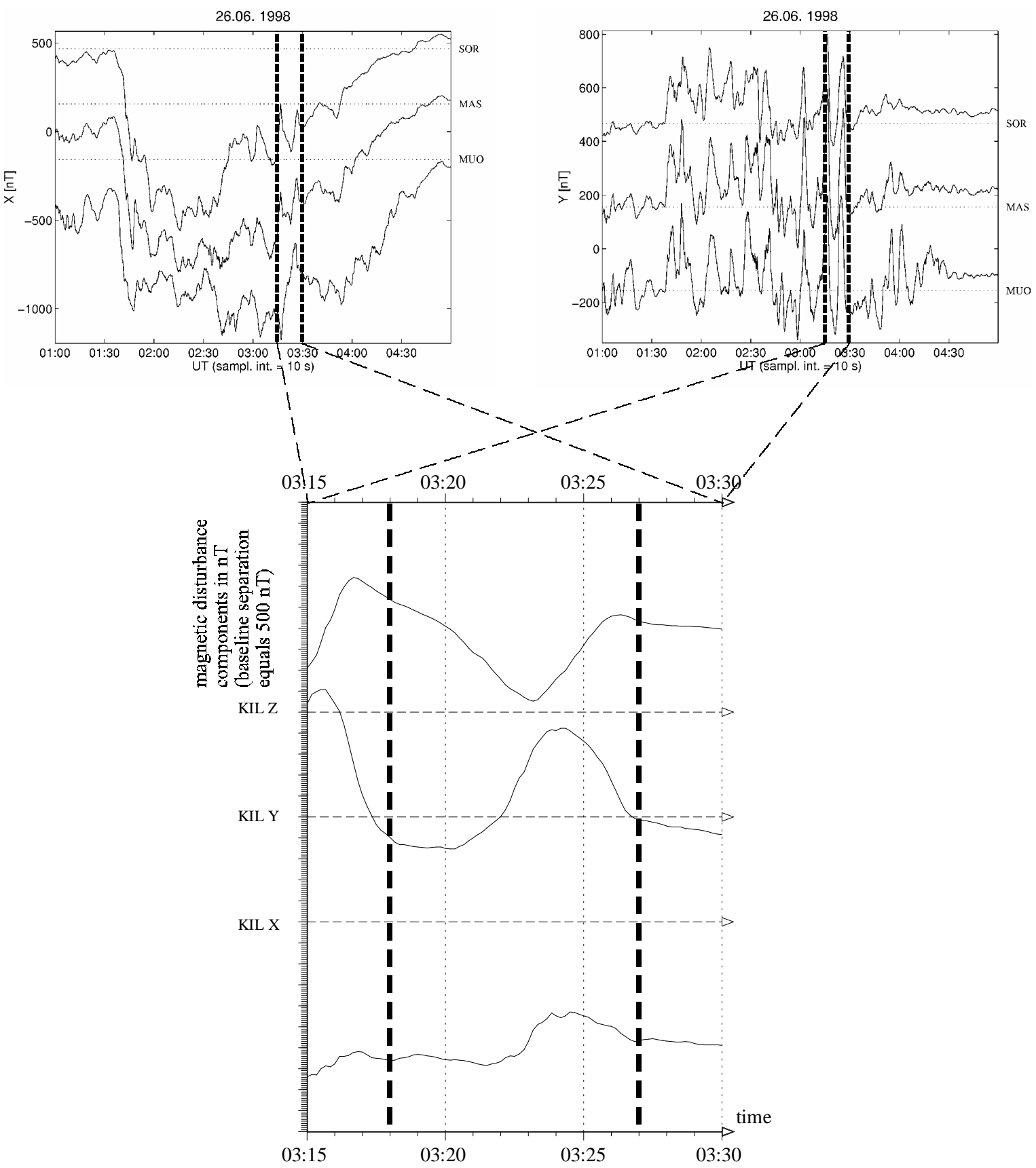

Fig. 2. Upper panels: $X$ (northward, left panel) and Y (eastward, right panel) components of the magnetic field disturbance at three meridionally aligned IMAGE stations, for the whole substorm period during which the event analysed here took place; lower panel: X, Y, and Z (downward) components of the magnetic field disturbance measured at Kilpisjärvi (KIL) on 26 June 1998; the vertical dashed lines enclose the time interval studied in detail in this paper. In all panels, the dashed or dotted horizontal lines are the baselines for the respective magnetic disturbance components.

but less clearly. Thus, we observe the typical signature of omega bands in a magnetogram as stated in Sect. 1. The vertical lines in the lower panel of Fig. 2 mark the time interval from 03:18-03:27 UT that we have chosen for detailed analysis in this study. As can be seen most easily from the $\mathrm{Y}$ component, this interval corresponds almost exactly to one period of the Ps6 pulsation related to the omega band which can be estimated to last $\sim 8 \min 30 \mathrm{~s}$.
In Fig. 3, the spatio-temporal variation of the magnetic field during our analysis interval has been represented by the equivalent current vectors just below the ionospheric plane $\boldsymbol{J}_{\text {eq,ion }}$ (e.g. Untiedt and Baumjohann, 1993). These vectors have been derived from the ground magnetic disturbance field using the Spherical Elementary Current System (SECS) method (Amm and Viljanen, 1999). During this procedure, $\boldsymbol{J}_{\text {eq,ion }}$ is partly also derived on areas which are not in an 




Fig. 3. Ionospheric equivalent currents (vectors) and UVI emissions (colour plots) for our detailed analysis interval. Plots around full minutes are organised from left to right with proceeding time, and according to the available UVI image: LBHS filter: upper row; LBHL filter: lower row; no UVI images: central row. The equivalent currents are averaged with respect to the UVI integration periods noted above each plot.

immediate vicinity of the ground magnetometers. The reliability of this approach has been confirmed by Pulkkinen et al. (2003). Since $\boldsymbol{J}_{\text {eq,ion }}$ inside the area shown in the figure also influences the magnetic field outside of it, all magnetic stations shown in Fig. 3 have been used. In addition, the colour panels show the UVI measurements in the area of Northern Scandinavia. As the UVI camera operates alternately with the LBHL and LBHS filters for this event, both image types are alternating in the time series. For the full minutes around which no UVI data are available, only $\boldsymbol{J}_{\text {eq,ion }}$ is shown. These data are arranged in three different rows such that time proceeds from left to right. When looking at a series of LBHL and LBHS images it is important to keep in mind that the same ionospheric feature may appear somewhat different in them due to their different energy and absorption characteristics as explained above. While the ground-based instruments have a time resolution of $20 \mathrm{~s}$, the UVI integration time is $37 \mathrm{~s}$ for our event. In order to make the presentation of $\boldsymbol{J}_{\text {eq,ion }}$ and the UVI images most consistent, we have averaged $\boldsymbol{J}_{\text {eq,ion }}$ over the UVI integration time periods in Fig. 3.
Also $\boldsymbol{J}_{\text {eq,ion }}$ shows the typical signature expected for omega bands: The substorm westward (equivalent) electrojet with maximum current amplitudes of $\sim 2 \mathrm{~A} / \mathrm{m}$ shows a meandering behaviour such that around 03:23 UT when the $\mathrm{Z}$ component minimum at KIL indicates that the central "tongue" of the omega band is above the station, $\boldsymbol{J}_{\text {eq,ion }}$ exhibits an anticlockwise vorticity and vectors with larger amplitudes (up to $\sim 1.3 \mathrm{~A} / \mathrm{m}$ ) shift polewards to $\sim 71^{\circ}$ latitude. Oppositely, around 03:26 UT when the $\mathrm{Z}$ component maximum indicates that the KIL magnetometer is located in the regions between the tongues, a clockwise vorticity is observed and the largest $\boldsymbol{J}_{\text {eq,ion }}$ vectors are concentrated at the equatorward border of the area shown. As can most easily be seen from the $\boldsymbol{J}_{\text {eq,ion }}$ signature of the tongues, the equivalent current structure is moving eastward over the MIRACLE area. From this signature, the velocity can be estimated to $\sim 770 \mathrm{~m} \mathrm{~s}^{-1}$, well in the typical range of omega bands.

The UVI camera on Polar observes an eastward moving form with enhanced intensities reaching about $2.5 \mathrm{kR}$ at most. This form intrudes to the southwestern edge of the displayed area at 03:20 UT, and covers the equatorial part of 
031739-031816 UT

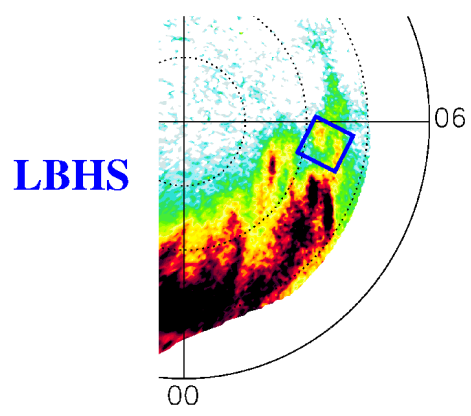

032043-032120 UT

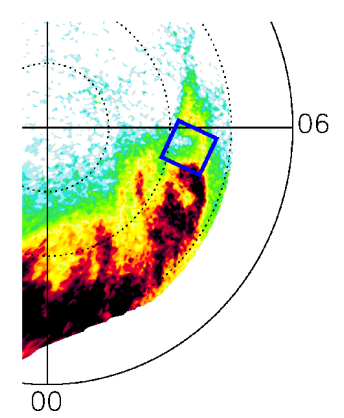

032347-032424 UT

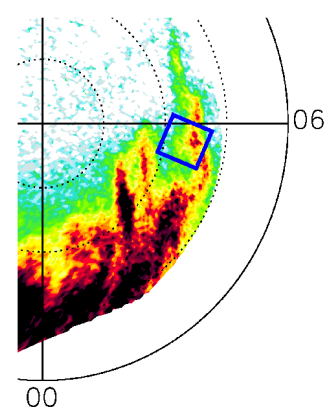

032651-032728 UT

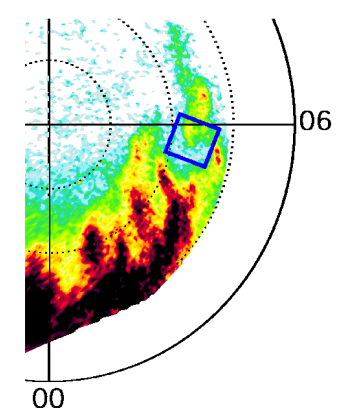

031930-032007 UT

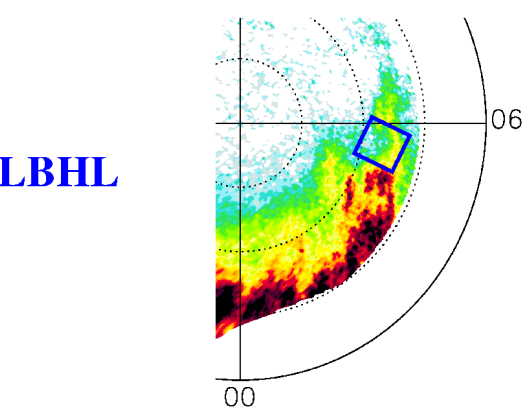

032234-032311 UT

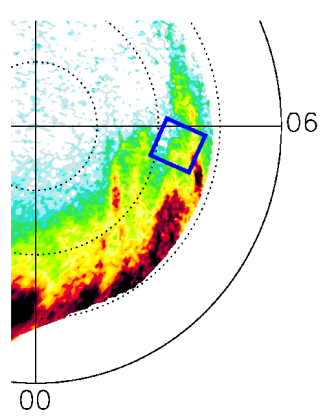

032538-032615 UT

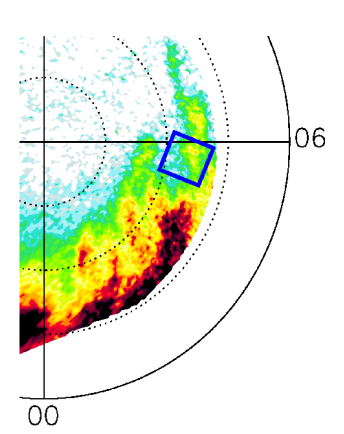

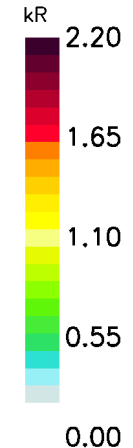

Fig. 4. Global UVI emissions in the morning sector. The MIRACLE area displayed in Fig. 3 is marked by the blue frames.

that area up to $\sim 71^{\circ}$ latitude as a southwest-northeast aligned strip at 03:24 UT. This feature is well aligned with the westward flank of the tongue of the omega band as determined

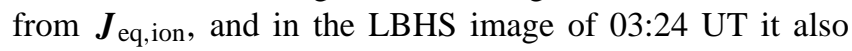
covers its central part. Outside this intensification the UVI intensities are considerably smaller, particularly at the poleward side of our area. As discussed above, the time steps 03:18 UT and 03:26 UT correspond to about the same phase of the omega band evolution as judged from the magnetometer data in Fig. 2. It is remarkable that structurally also the UVI images of these two time steps show similar features, except for some equatorward shift of the structure. As is to be expected (e.g. Frey et al., 1999), the observed UVI signature is not exactly identical with the type of appearance typically seen in visual band optical data. Still, the eastward movement of a tongue-like feature and the darker areas around it are clearly discernable.

In order to put our observations into a global context, Fig. 4 shows UVI images of the whole morning side auroral bulge. Again, LBHS and LBHL images are alternating. The MIRACLE region on which $\boldsymbol{J}_{\text {eq,ion }}$ is shown in Fig. 3 is marked by a blue box. A clearly developed substorm auroral bulge is visible, with periodic tongue or finger-like poleward extensions which are drifting eastward, as they are characteristic for auroral omega bands or torches (e.g. Paschmann et al., 2003, their Sect. 6.3). The LBHS images generally show a larger intensity of the radiation, indicating a mean energy of the precipitating particles in the range of $\sim 2-5 \mathrm{keV}$ (Ger- many et al., 1998a). The undulations are strongest in the $\sim$ 01:00-04:00 MLT sector. During the event studied here, MIRACLE is located at the morning side edge of the substorm auroral bulge between $~ 05: 00-06: 00$ MLT where the amplitude of the mentioned undulations is decreasing, but they are still present, as most clearly seen from Fig. 3.

Figure 5 shows the time series of STARE observations of the ionospheric electric field $\boldsymbol{E}$. These data have been obtained by an inverse distance interpolation of the original merged radar data, which have a resolution of $\sim 20 \mathrm{~km} \times 20 \mathrm{~km}$, to the grid of our analysis. The electric field is mainly directed southward as expected in the westward electrojet domain, and its magnitudes vary from $\sim 30$ $75 \mathrm{mV} / \mathrm{m}$. In accordance with the models of Buchert et al. (1988, 1990) and Amm (1996), the largest electric fields are observed at the poleward edge of the omega structures. From 03:21-03:24 UT when the tongue of the omega band is moving over the measurement area according to our previous discussion, a negative divergence of $\boldsymbol{E}$ is observed inside this area. At 03:18 UT and 03:19 UT, in the eastern part of the STARE field of view, the electric field has a substantial eastward component which causes a positive divergence of $\boldsymbol{E}$ in this region. This electric field structure repeats, although less pronounced, at 03:26 UT and 03:27 UT, i.e. when the main part of the omega band tongue has passed the field of view eastward. This is consistent with expected behaviour of the electric field westward of a tongue in the models of Opgenoorth et al. (1983a) and Buchert et al. (1990). 

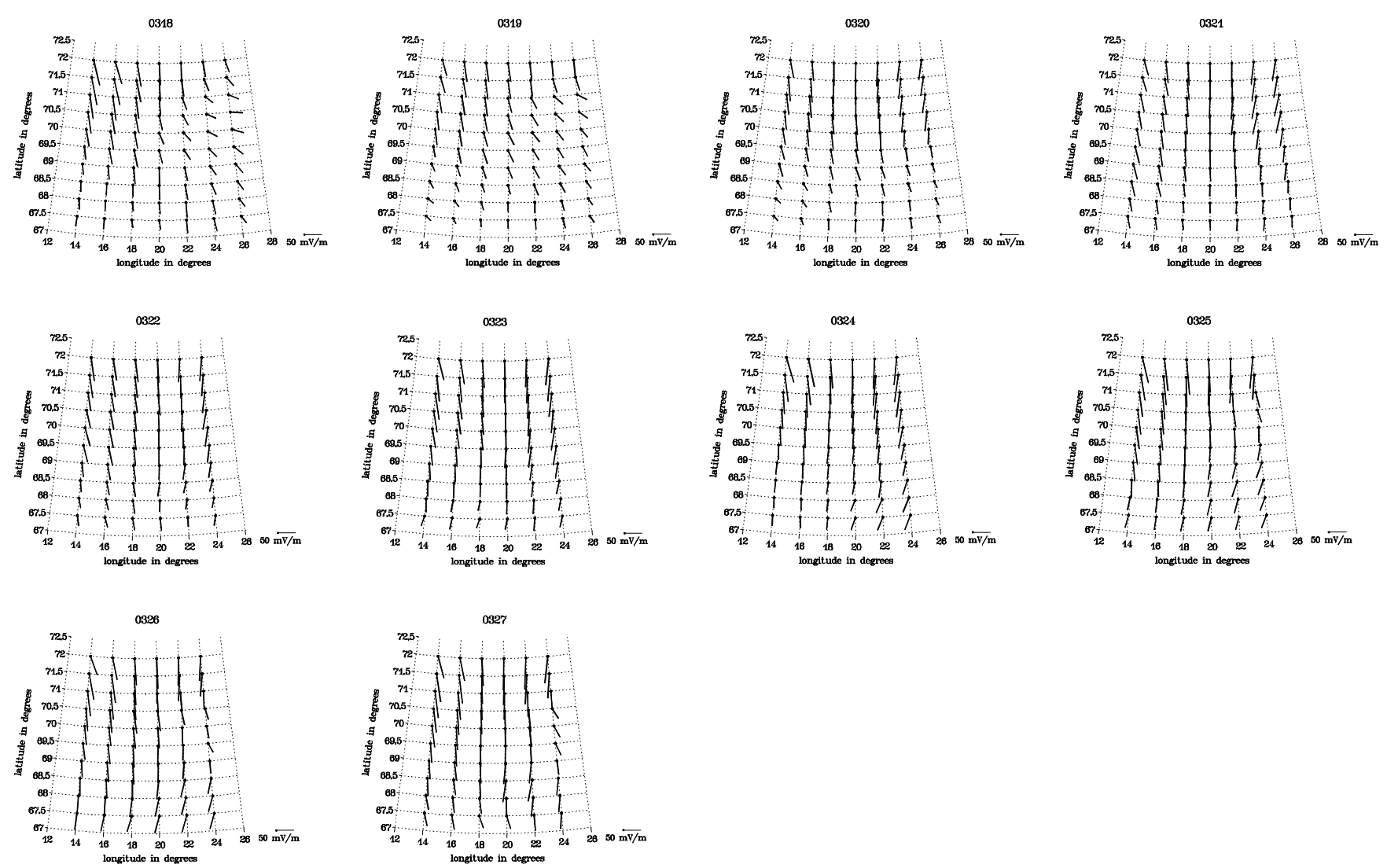

Fig. 5. Electric field measurements of the STARE radar.

However, a westward electric field component of similar magnitude eastward of the omega band as predicted by these mostly symmetrical models is not observed here.

It should be noted that the STARE radar may at times underestimate very large electric fields. However, as we observe magnitudes of $\boldsymbol{E}$ up to $75 \mathrm{mV} / \mathrm{m}$, it is unlikely that a significant underestimation has happened in our case. Further, if large electric fields were underestimated, this would mostly mean that the ionospheric conductance would be overestimated in areas of already very low conductances (see analysis results in Sect. 4). We therefore conclude that a possible effect of this kind is insignificant for our study.

\section{Analysis techniques}

Two techniques to derive ionospheric conductances are used for our analysis: the two-dimensional (2-D) method of characteristics and a technique to derive the conductances from the UVI and PIXIE data. The method of characteristics (Inhester et al., 1992; Amm, 1995, 1998) combines spatial data of $\boldsymbol{J}_{\text {eq,ion }}$ (Fig. 3) with data of $\boldsymbol{E}$ (Fig. 5) to solve a differential equation for the Hall conductance $\Sigma_{H}$. For this, an estimate of the Hall to Pedersen conductance ratio $\alpha$ is needed which we obtain here from the analysis of the UVI and PIXIE data (see below). With the resulting $\Sigma_{H}$ and the input data, the true horizontal currents $\boldsymbol{J}$ and the field-aligned currents $j_{||}$can then be calculated. In contrast to the "trial and error" method mentioned in Sect. 1, the method of characteristics is a forward method, information on the uniqueness of the solution is available, and there is no need to extend the analysis area with respect to the area of instantaneous measurements of the input data.

The ionospheric Hall and Pedersen conductances can also be derived from UVI and PIXIE data, using a computer code developed by the University of Maryland. This code is based on the TANGLE code (Vondrak and Baron, 1976; Vondrak and Robinson, 1985), and it models ionospheric conductances by taking precipitating electron energy spectra as input. A detailed description of the code is provided by Aksnes et al. (2002, 2004). By combining UVI and PIXIE data, we can derive precipitating electron energy spectra within an energy range of $\sim 0.1$ and $100 \mathrm{keV}$, meaning that all electron energies of importance for the conductances are included (Østgaard et al., 2001). The Pedersen conductivity peaks around $125 \mathrm{~km}$. In this height region electrons in the range of a few $\mathrm{keV}$, well measured by the UVI camera, deposit their energy (Rees, 1963). The Hall conductivities are largest below $110 \mathrm{~km}$, and are therefore due to more energetic electrons of some tens of $\mathrm{keV}$, well measured by PIXIE. In this paper, this technique is solely used to infer values of $\alpha$ given as input for the method of characteristics. 
In a statistical sense, i.e. when averaging the results with respect to the temporal $(\sim 4.5 \mathrm{~min})$ and spatial $(\sim 600$ $900 \mathrm{~km}$ ) resolution of the PIXIE instrument, the groundbased results agree reasonably well with the conductances obtained from the UVI/PIXIE technique, as has recently been shown by Aksnes et al. (2004b). For this study of several substorm events, including the one analysed in detail in this paper, the one-dimensional version of the method of characteristics was used (Inhester et al., 1992; Sillanpää, 2002).

This paper focuses on the discussion of the results of the two-dimensional method of characteristics for the period presented in Sect. 2. The optical data is mainly used as a qualitative background information, except for the calculation of $\alpha$ as discussed above. For each time step in the analysis, the $\alpha$ value obtained from the UVI/PIXIE technique is assumed uniformly over the analysis area. Although Amm (1996) has shown that a variable $\alpha$ improves the modeling of an omega band, we decided to use a realistic $\alpha$ value, but being bound to the coarse resolution of PIXIE rather than introducing spatially varying, but possibly unrealisitic models for this parameter. Possible errors related to a wrongly assumed $\alpha$ value have been discussed in detail by Amm (1995), using a model of an omega band (see his Fig. 5b) and found it to be marginal.

The AMIE procedure (Richmond and Kamide, 1988) is one of the most commonly used methods for deriving ionospheric electrodynamics. In contrast to the techniques mentioned above, AMIE is an optimisation method, i.e. the desired electrodynamic parameters are optimised such that they are as consistent as possible with all available measurements, using a least-square approach. This gives AMIE the flexibility to utilize many different data sets, and not every input data set has to cover the full analysis region, as it is required for forward methods that are based on the solution of algebraic or differential equations, like the method of characteristics. On the other hand, AMIE uses initial assumptions on both ionospheric conductances usually taken from statistically-based models and other statistical a priori information which reduces its ability to adequately represent single events in regions where the data coverage is sparse. Until now, AMIE has only been available for global-scale analyses.

\section{Analysis results and discussion}

The results of the analysis with the 2-D method of characteristics and the AMIE method are displayed as time series in Fig. 6. Note that the size of the analysis area for the method of characteristics changes within the time series: While for 03:18-03:21 UT, the whole STARE field of view (cf. Fig. 5) is displayed, for 03:22-03:27 UT the eastern border of the analysis area is set to $24^{\circ}$ longitude, as for these time steps substantial uncertainties in the solution were encountered at the easternmost grid column at $26^{\circ}$ longitude. The values of $\alpha$ that resulted from the UVI and PIXIE analysis and which are used for the calculation are 2.75 for $03: 18-03: 19$ UT, 2.4 for 03:20-03:25 UT, and 2.3 for 03:26-03:27 UT. Figure 6a shows the resulting $\Sigma_{H}$ distributions, the primary output of the method of characteristics, as isocontour plots. A poleward extending tongue-like region of enhanced $\Sigma_{H}$ values, slightly tilted in the northwest-southeastern direction, is seen to move eastward over the analysis region from 03:19 UT to $03: 25 \mathrm{UT}$. The maximum conductances inside the tongue are varying from $\sim 40$ to $60 \mathrm{~S}$ (Siemens) and are located most poleward between 03:21 and 03:23 UT. Starting from 03:26 UT, the maximum Hall conductances in the poleward part of the analysis area decrease, and the appearance of the conductance structure becomes more diffuse. At the flanks on the moving tongue, regions with low $\Sigma_{H}$ values below $5 \mathrm{~S}$ are visible. Steep conductance gradients, particularly in the longitudinal direction, are present between the tongues and the adjacent regions. The second area where enhanced conductances are observed with magnitudes comparable to the maximum ones in the tongues is the equatorward border of our analysis area, the "base" of the omega bands. The conductance structure in this region does not follow the movement of the tongues.

The resulting true ionospheric currents $J$ (Fig. 6b) are generally pointing southwestward, as a consequence of the mostly southward electric field that generates southward Pedersen and westward Hall currents. The maximum current density reaches over $4000 \mathrm{~mA} / \mathrm{m}$ in the area of the tongues of conductance enhancements around 03:23 UT. In response to the steep conductance gradients, similar steep gradients in zonal direction are also seen in $\boldsymbol{J}$, except for in the area of the base of the omega bands. The most obvious difference between the equivalent (Fig. 3) and the true currents is that the latter do not show a meandering signature like the former do, but are essentially disrupted when they encounter a low conductance area, and reappear again in the subsequent high conductance area.

Consequently, this change in $\boldsymbol{J}$ needs to be moderated by upward (downward) field-aligned currents $j_{\|}$(FAC) at the westward (eastward) flank of the high conductance regions (Fig. 6c; crosses denote downward, squares upward FAC). Alternating, meridionally aligned (with a slight tilt in northwest-southeast direction) sheets of FAC are visible which are comoving with the conductance tongue structures. The upward FAC vary in magnitude between $\sim 15-$ $25 \mu \mathrm{A} \mathrm{m}^{-2}$, while the downward FAC are on average smaller and mostly do not exceed $10 \mu \mathrm{A} \mathrm{m}^{-2}$ (for a more detailed discussion on the FAC balance and current closure, see below). These alternating FAC sheets, together with the horizontal currents, cause the characteristic meandering signature observed in $\boldsymbol{J}_{\text {eq,ion }}$. Note that some numerical diffusion may be introduced when calculating the $j_{\|}$as the horizontal divergence of $\boldsymbol{J}$.

For comparison, the global Hall conductance results of the AMIE method are shown in Fig. 6d for three time steps with $10 \mathrm{~min}$ intervals and a time resolution of $5 \mathrm{~min}$. The central time step 03:20-03:25 UT falls into the period analysed in detail above, while the other time steps are just before and after our main analysis period. The location of the 

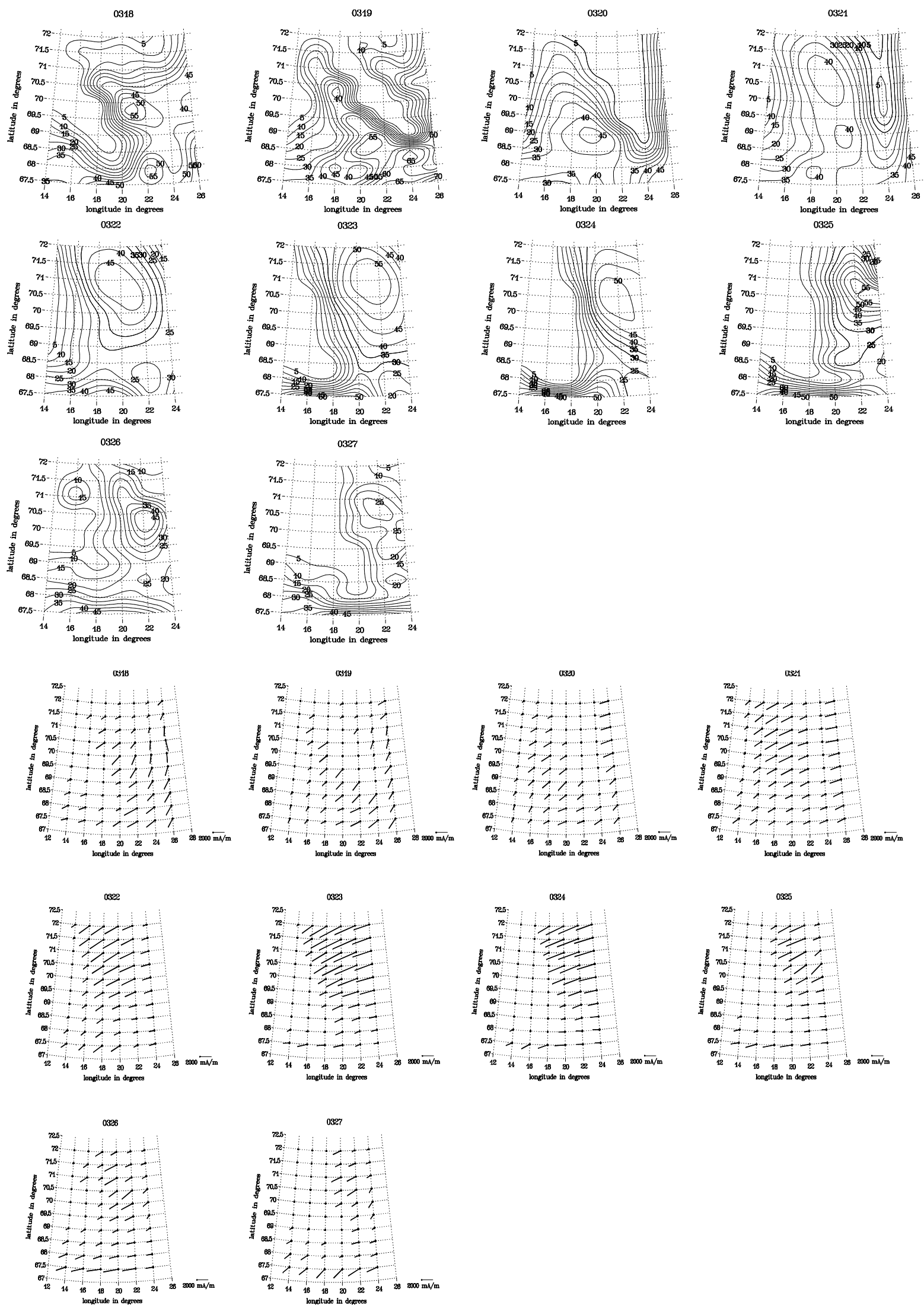

Fig. 6. Analysis results of the method of characteristics (panels a-c) and the AMIE method (panel d). (a) Hall conductance $\Sigma_{H}$; (b) True ionospheric currents $\boldsymbol{J}$; (c) field-aligned currents $j_{\|}$(crosses denote downward, squares upward currents; dots give the positions of isolated conductance maxima above $69^{\circ}$ of latitude, cf. panel a); (d) Global Hall conductance distribution in the morning sector. 

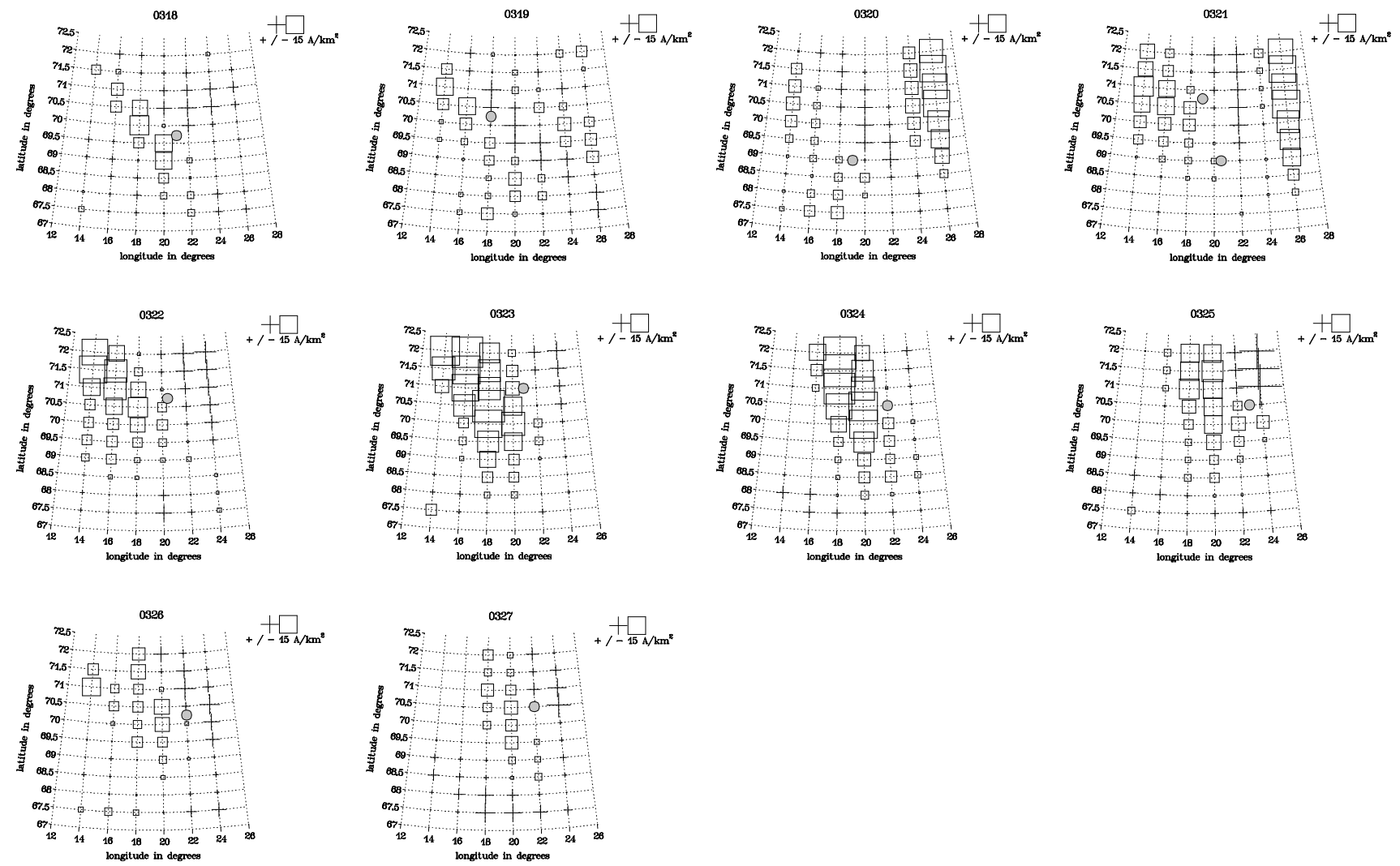

0310 - 0315 UT

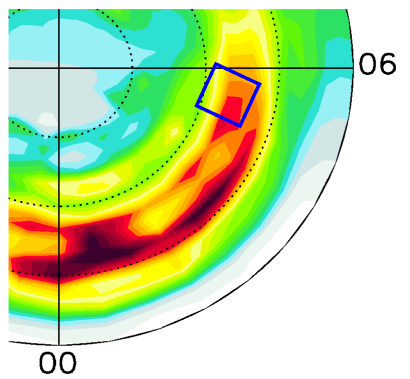

0320 - 0325 UT

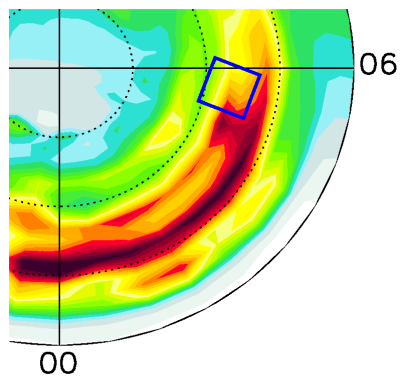

0330 - 0335 UT
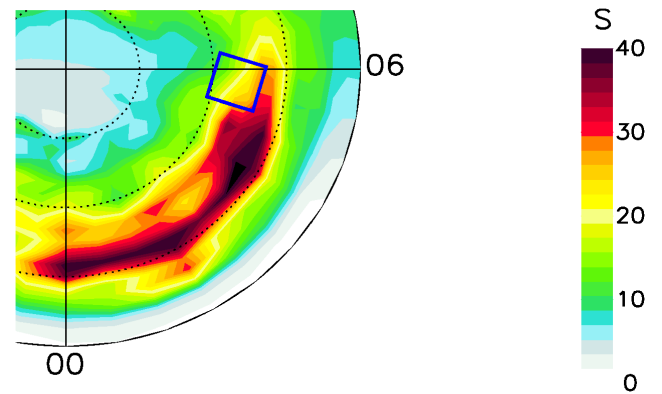

Fig. 6. Continued.

MIRACLE network is marked by a blue rectangle similar to that in Fig. 4. The inputs for this method are ground magnetic field data from 141 magnetometers (65 of which are located in the high-latitude Northern Hemisphere), the UVI and PIXIE data from the Polar satellite (where the UVI data has been smoothed to the resolution of the PIXIE instrument, see Sect. 2), and a priori information from the statistical conductance model of Fuller-Rowell and Evans (1987), as well as from the Millstone Hill statistical convection model of Foster et al. (1986). Obviously, the temporal and spatial resolution of the AMIE method does not allow for a direct comparison with the results of the method of characteristics. However, the following features are important in order to confirm our mesoscale results and to link them to the global situation. Also AMIE sees undulations in the conductance structure at the poleward side of the substorm auroral bulge which are moving eastward, most discernably in the 01:00-04:00 MLT sector. The maximum Hall conductance of $\sim 35 \mathrm{~S}$ that results from AMIE in the MIRACLE region during the 03:20-03:25 UT interval is in a reasonably similar range compared to the results of the 2-D method of characteristics (Fig. 6a), if some averaging with respect to the coarser resolution of AMIE is considered. Additionally, the AMIE results indicate that the overall global conductance level inside the substorm bulge stays fairly unchanged over the time interval that we analyse in detail.

When comparing the $\Sigma_{H}, \boldsymbol{J}$ and $j_{\|}$distributions shown in Fig. 6a-c with those of earlier models, it needs to be 
(a)

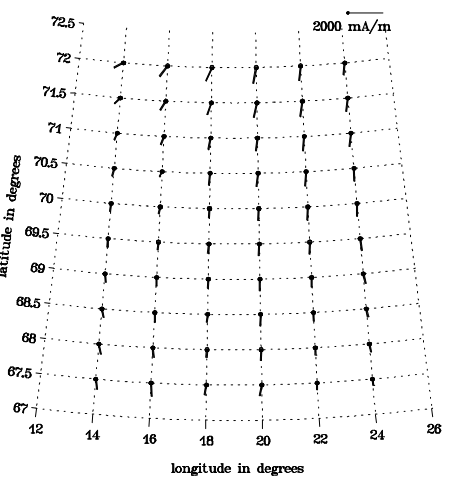

(c)

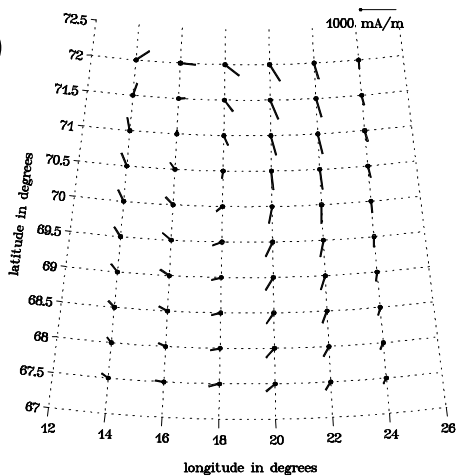

(e)

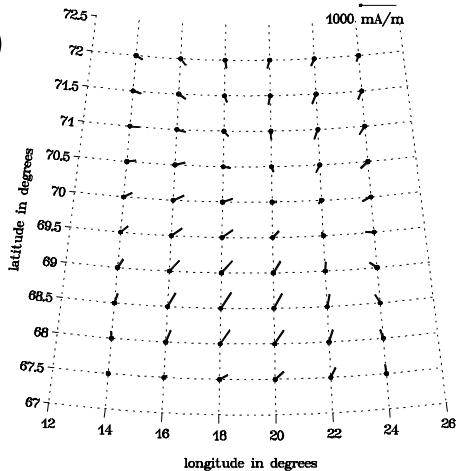

(b)

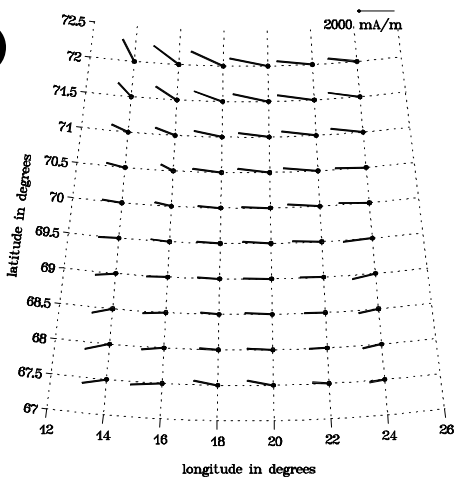

(d)

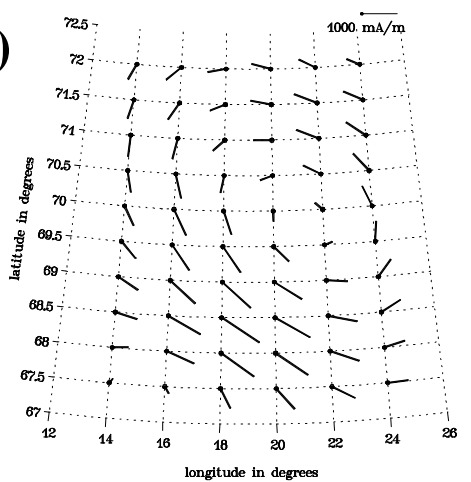

(f)

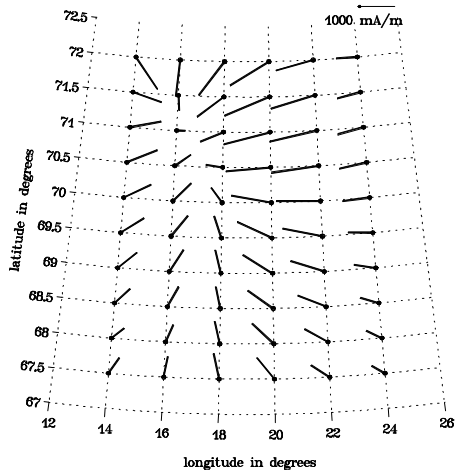

Fig. 7. Decomposition of the true ionospheric currents $\boldsymbol{J}$ at 03:23 UT into a part which is curl- and divergence-free in the analysis area ("lap", upper row), a part which is divergence-free but has curls in the analysis area ("df", middle row), and a part which is curl-free but has divergences in the analysis area ("cf", lower row), seperately performed for the Pedersen currents $\boldsymbol{J}_{P}$ (left column) and the Hall currents $\boldsymbol{J}_{H}$ (right column).

taken into account that naturally the output of a forward method that is directly driven by instantaneous observations is less symmetrically organised than theoretical models or other models that are only partly data-based. Moreover, all detailed spatial models of omega bands mentioned in Sect. 1 explicitly or implicitly assume that the structures are stationary while moving over the instrument network used. Although in the time series results of Fig. 6, we observe coherently eastward moving structures, an exact stationarity is not given. In spite of this, our resulting $\Sigma_{H}$ distributions of the omega bands' tongues structurally agree in many respects with the EISCAT and magnetometer based models by Buchert et al. (1990) and Amm (1996): The enhanced conductance tongues are extending $\sim 400 \mathrm{~km}$ poleward from their base, and the conductance maxima in the center of the tongues and in the base have about the same magnitude. At the flanks of the tongues, steep conductance gradients are present in both longitudinal directions and in poleward direction. Also, the longitudinal extent of the tongues, estimated to be $\sim 380 \mathrm{~km}$ from the $03: 21$ UT plot at $70^{\circ}$ latitude, agrees well with $\sim 450 \mathrm{~km}$ for the models mentioned. (Note that our estimate also agrees well with the value of $\sim 390 \mathrm{~km}$ which one obtains from the omega band period and velocity estimates based on the equivalent current patterns in Sect. 2.) These values are, however, clearly smaller than the $800 \mathrm{~km}$ given by Lühr and Schlegel (1994), while in the study 
of Opgenoorth et al. (1983a) their extent is only $\sim 200 \mathrm{~km}$. These differences indicate that omega bands may exist on a range of different wavelengths. The most notable difference between our results and the previous models appears in the current system and is caused by the fact that we do not observe a continuous strong eastward rotation of $\boldsymbol{E}$ at the western flank of the tongues. Hence, in contrast to the models of Opgenoorth et al. (1983a), Buchert et al. (1990), and Amm (1996), we do not obtain a strong southward component of $\boldsymbol{J}$ there, but the westward currents are diverted to upward flowing FAC. Within our event, a larger eastward rotation of $\boldsymbol{E}$ and correspondingly southward directed $\boldsymbol{J}$ are observed only during the 03:18 and 03:27 UT time steps, but these signatures appear to be non-stationary. On the first view our resulting current system (Fig. $6 \mathrm{~b}$ and c) may be described as a sequence of longitudinally aligned current wedges with westward to southwestward flowing horizontal ionospheric currents. In the following, we will analyse some properties of this current system in more detail.

Obviously, our resulting current system neither corresponds one-to-one with the "system 1" by Kawasaki and Rostoker (1979), which consists mainly of southward currents, nor with "system 2" by Gustafsson et al. (1981), which assumes uniform conductances. In order to analyse the relative importance of the basic current system components, we perform a division of the total current system into three parts: A part which has divergences in the analysis region, but is curl-free (subscript "cf"), a part which has curls in the analysis region, but is divergence-free (subscript "df"), and a part that has neither curls nor divergences inside the analysis area (subscript "lap"). Note that such a subdivision can uniquely be applied to any given vector field on a sphere. In Fig. 7 this subdivision is separately performed for the Pedersen currents $\boldsymbol{J}_{P}$ (left column) and the Hall currents $\boldsymbol{J}_{H}$ (right column) for the time step 03:23 UT. We have chosen this time step since the major part of an enhanced conductance tongue is present in the eastern central part of the analysis area, and also the steep conductance gradients at its western flank are well inside this region (compare Fig. 6a). A similar analysis has been performed by Amm (1996) on the EISCAT and magnetometer based current system modeled in that study (his Fig. 3). Our results can thus directly be compared with that figure. Figures $7 \mathrm{a}$ and $\mathrm{b}$ show the current parts $\boldsymbol{J}_{\mathrm{P} \text {,lap }}$ and $\boldsymbol{J}_{\mathrm{H}, \text { lap }}$, respectively. As in the analysis of Amm (1996), these current systems represent the background westward electrojet with southward Pedersen and westward Hall currents. The divergence-free current system is dominated by an anticlockwise vortex of $\boldsymbol{J}_{H, d f}$ which is centered $\sim 1^{\circ}$ equatorward of the conductance maximum (Fig. $7 \mathrm{~d}$ ) and reaches a maximum amplitude of $\sim 1200 \mathrm{~mA} \mathrm{~m}^{-1}$ (note the different scales in Figs. 7a-b and Figs. 7c-f). This current system causes the characteristic ground magnetic effect of a positive Y component at the western flank of the conductance tongue, and a negative one at its eastern flank. Its signature is partly opposed by a clockwise vortex of $\boldsymbol{J}_{P, d f}$ (Fig. 7c) which is centered westward of the conductance maximum, but is generally considerably weaker than $\boldsymbol{J}_{H, d f}$. The curl-free current system which is magnetically invisible below the ionosphere (e.g. Fukushima, 1976) is also dominated by its Hall current part, $\boldsymbol{J}_{H, c f}$ (Fig. 7f), which shows a negative divergence in the region of the western flank of the conductance tongue. Its maximum current density is with $\sim 1300 \mathrm{~mA} \mathrm{~m}^{-1}$ comparable to the one of $\boldsymbol{J}_{H, d f}$. $\boldsymbol{J}_{P, c f}$ (Fig. 7e) is much weaker and exhibits a negative divergence closer to the center of the conductance tongue.

The contribution of system 2 is represented by the $\boldsymbol{J}_{P, c f}$ and $\boldsymbol{J}_{H, d f}$ current systems, since if only system 2 was present, $\boldsymbol{J}_{P}=\boldsymbol{J}_{P, c f}$ and $\boldsymbol{J}_{H}=\boldsymbol{J}_{H, d f}$ would hold. As in the case of Amm (1996), this current system produces the characteristic ground magnetic signature. Here it comprises $\sim 50 \%$ of the non-background currents. The polarity of this system changes during the time series as expected from the changes in $\boldsymbol{J}_{\text {eq,ion }}$ (Fig. 3): for example, at 03:18 UT, $\boldsymbol{J}_{H, d f}$ exhibits a clockwise vortex and $\boldsymbol{J}_{P, c f}$ a positive divergence (not shown). The remaining part of the current system at 03:23 UT, however, shows a clear difference to the Amm (1996) results. There, a northwest-southeast aligned Cowling channel, in accordance with system 1, was detected at the western flank of the tongue, as indicated by $\boldsymbol{J}_{P, d f} \| \boldsymbol{J}_{H, d f}$ and $\boldsymbol{J}_{P, c f} \approx-\boldsymbol{J}_{H, c f}$. Both conditions are not fulfilled in Fig. 7. Instead, the current system of $\boldsymbol{J}_{P, d f}$ and $\boldsymbol{J}_{H, c f}$ exhibits the signature of the western end of a westward current wedge consisting of Hall currents. Thus, we conclude that the current system at 03:23 UT can be described as a superposition of a system 2 type current and the westward end of a westward Hall current wedge. Note that as $\boldsymbol{J}_{H, c f}$ produces no ground magnetic effect, the latter part is largely magnetically invisible on the ground.

In Fig. 8 we analyse the FAC distribution at 03:23 UT by decomposing the total FAC (compare Fig. 6c) into

$j_{||}=\Sigma_{P} \nabla_{h} \cdot \boldsymbol{E}+\nabla_{h} \Sigma_{P} \cdot \boldsymbol{E}+\nabla_{h} \Sigma_{H} \cdot(\hat{z} \times \boldsymbol{E})$,

where the subscript $h$ denotes the horizontal part of the nabla operator, and $\hat{z}$ is the unit vector in downward direction. The three terms of the right-hand side of this equation are called "term 1" to "term 3" here. While term 1 is related to the divergence of $\boldsymbol{E}$, terms 2 and 3 are proportional to the gradients of the Pedersen and Hall conductance, respectively. Term 1 contributes to upward FAC in the area of the enhanced conductance tongue of up to $\sim 4 \mu \mathrm{A} \mathrm{m}^{-2}$ magnitude. Both terms related to the conductance gradients exhibit upward FAC at the western flank of the tongue, and some downward FAC are present at the northeastern edge of the analysis area. However, term 3, related to the gradients of the Hall currents, is with upward FAC amplitudes up to $\sim 20 \mu \mathrm{A} \mathrm{m}^{-2}$ by far dominating both other terms. This result underlines the importance of the conductance gradients for the resulting current system (as for uniform conductances only term 1 would be non-zero), and the dominating role of the westward directed Hall current wedge for the FAC related to our event. Note that in some studies (e.g. Sofko et al., 1995), term 1 has been called "magnetospheric FAC" while terms 2 and 3 have been named "ionospheric FAC", although it appears difficult to justify such a separation in terminology in a coupled 

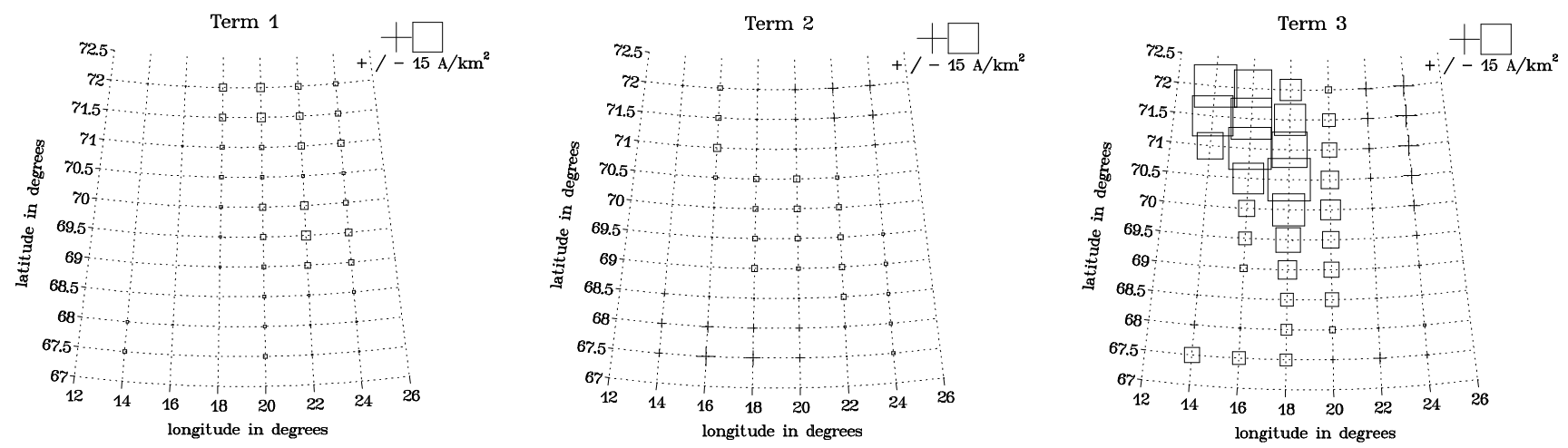

Fig. 8. Decomposition of the total FAC density $j_{||}$at 03:23 UT into a term related to the divergences of the electric field (left panel), a term related to the gradients of the Pedersen conductance (middle panel), and a term related to the gradients of the Hall conductance (right panel); crosses denote downward, squares upward currents; for more details see text.

system. While in those studies terms 2 and 3 are usually neglected, they contribute more than $85 \%$ of the total FAC in our case at 03:23 UT.

The above result is further specified for the whole time series of our analysis in Fig. 9. The dots show the part of the total FAC that connect to Hall currents $\left(\left|\nabla_{h} \cdot J_{H}\right|\right)$ in percent (scale on the right side of the graph), integrated over the analysis area. The remainder connects to ionospheric Pedersen currents. Throughout the whole event, the FAC part connecting to Hall currents dominates with $\sim 66-84 \%$. The crosses denote the absolute FAC $\left(\left|j_{||, u p}\right|+\left|j_{||, \text {down }}\right|\right)$ integrated over the analysis area for each timestep (scale on the left side of the graph). These total absolute FAC are varying from $\sim 1.5 \mathrm{MA}$ in the beginning and end of the analysed period to the maximum value of $\sim 2.3 \mathrm{MA}$ at $03: 23 \mathrm{UT}$. We note that these values are of a similar order of magnitude as the total upward FAC diverted in a westward traveling surge, the westward end of the substorm electrojet, as estimated to $\sim 1$ MA by Opgenoorth et al. (1983b) and $\sim 2.5$ MA by Gjerloev and Hoffman (2002). This indicates that a significant part of the substorm electrojet in the morning sector is intermediately disrupted due to the zonally alternating high and low conductance structures related to the omega bands in the morning sector of the substorm auroral bulge. Generally, our results are in good agreement with the finding of $\mathrm{Lu}(2000)$ that the FAC connected to the Hall currents amounts to 30$50 \%$ of the total FAC, seen over the whole substorm bulge.

An interesting and open question that arises is how the FAC are balanced and how the current closure in the ionosphere is established. A number of earlier papers assume explicitly or implicitly that the upward and downward FAC associated with omega bands are purely closed by zonally flowing ionospheric currents (e.g. Yamamoto et al., 1993; Lühr and Schlegel, 1994). In this case one would expect that if the FAC are observed in a certain fixed region over which the omega bands are moving in a zonal direction, they would balance over one cycle of the omega bands, except for possible small deviations due to effects of partial non-stationarity. Note that for a common omega band model with a zonal sym- metry, like the one of Lühr and Schlegel (1994, their Fig. 9), this balance is also expected in any subrange of latitudes and is thus independent of the question of whether or not the observations cover the full latitude range of the structures. Figure 10 shows the integrated upward and downward FAC for each time step of our analysis (marked by crosses and squares, respectively), and the integrated total FAC (marked by dots). Except for the time steps 03:18 UT, 03:26 UT and 03:27 UT, the integrated total FAC are upward throughout our event. The upward FAC tend to become larger when the conductance tongue is in the center of the analysis area, with a maximum of $\sim 1.9 \mathrm{MA}$ at 03:23 UT, while the downward FAC are simultaneously becoming smaller with a mimimum of $\sim 0.5 \mathrm{MA}$ at 03:24 UT. (An exception is the time step 03:22 UT, where part of the FAC structure appears to move out of our analysis region in the poleward direction.) Summed up over the whole omega band cycle, an excess of 4.6 MA of upward FAC exists, which is far too large to be explained by any non-stationary effects, although our event somewhat fades out after 03:25 UT. This can be seen from the following rough estimate: The Hall conductance maximum decreases from $\sim 55 \mathrm{~S}$ at $02: 35 \mathrm{UT}$ and before to $\sim 25 \mathrm{~S}$ at 03:27 UT. Since the FAC are dominated by the gradient of the Hall currents for our event as shown before, they are roughly proportional to the value of that maximum. If we would scale the FAC at 03:26 and 03:27 UT with the ratio between $55 \mathrm{~S}$ and the respective FAC maximum at these time steps, we would get an additional amount of $\sim 1.2 \mathrm{MA}$ of downward FAC, much less than the calculated upward FAC excess.

The excess upward FAC of $\sim 4.6 \mathrm{MA}$ should be compared with the total of $\sim 11.9 \mathrm{MA}$ of upward FAC summed over our analysis period, indicating that the excess of upward FAC amounts to $\sim 39 \%$. If we include a correction with respect to the temporal development of the event as estimated above, still the upward FAC excess amounts to $\sim 3.4 \mathrm{MA}$ or $\sim 29 \%$. Therefore we conclude that the FAC cannot be solely closed by zonally flowing ionospheric currents, but part of the upward FAC inside our analysis region have to be connected 


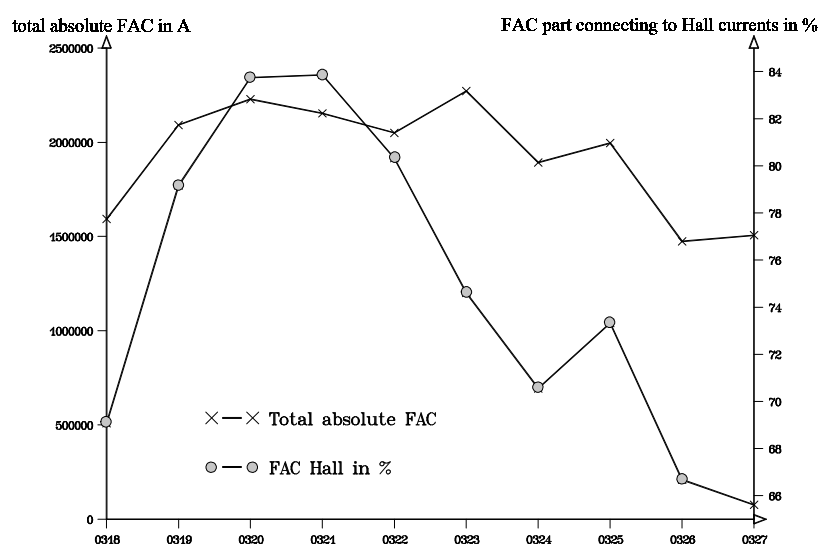

Fig. 9. Total absolute FAC in A (crosses, scale on the left side of graph) and percent of FAC connecting to ionospheric Hall currents in \% (dots, scale on the right side of the graph) as a function of time over the analysis interval.

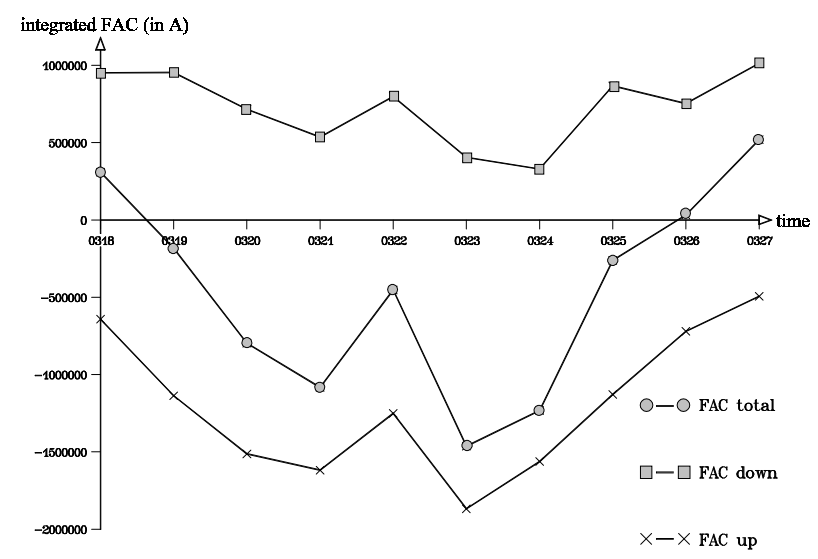

Fig. 10. Integrated upward FAC (crosses), integrated downward FAC (squares), and integrated total FAC (dots) in A over the analysis region, as a function of time over the analysis interval.

with downward FAC outside of it by currents flowing in meridional direction. Given the direction of $\boldsymbol{E}$, these additional downward FAC regions can only be located poleward of our analysis area. This is consistent with the fact that $\boldsymbol{J}$ shows an equatorward component at the poleward boundary of our analysis area throughout the event (Fig. 6b).

In addition, we have calculated the instantaneous FAC balance for a single omega band tongue within our analysis area. For this we have chosen the time step 03:21 UT since both flanks of the conductance tongue that is centered at $\sim 19^{\circ}$ longitude are well contained in our analysis region (Fig. 6a). When integrating, we neglect the FAC at the eastern boundary at 24 and $26^{\circ}$ latitude, as they obviously belong to a previous omega band tongue. The integration results in a total of $859 \mathrm{kA}$ of upward FAC and $534 \mathrm{kA}$ of downward FAC, underlining the imbalance mentioned before.

Figure 11 shows the Joule heating $W_{\text {Joule }}=\Sigma_{P} E^{2}$ for the time steps 03:18 UT and 03:23 UT. This definition of the Joule heating does not include possible effects of the neu- tral atmosphere (e.g. Fujii et al., 1999) which we cannot take into account since no data about neutral winds are available for our event. When comparing the Joule heating with the conductance structures of both time steps (Fig. 6a), it becomes obvious that both are following each other closely although the Joule heating is quadratically dependent on the electric field magnitude. This is due to the fact that $|\boldsymbol{E}|$ shows only small gradients in poleward direction during our event. At 03:23 UT, a maximum Joule heating of $\sim 120 \mathrm{~mW} \mathrm{~m}^{-2}$ is resulting at the poleward edge of the enhanced conductance tongue, while at 03:18 UT the maximum Joule heating amounts only to $\sim 35 \mathrm{~mW} \mathrm{~m}^{-2}$, close to the equatorward boundary of our analysis area. The total power of the Joule heating over the analysis region is $\sim 10 \mathrm{GW}$ at 03:23 UT. For comparison, the maximum power consumption in Finland under extreme winter conditions was $\sim 14 \mathrm{GW}$ in January 2003.

When vortical structures are present in the equivalent currents, as derived from the ground magnetic field disturbance, it is usual to take the $\mathrm{Z}$ component of the ground magnetic field as a qualitative proxy for the FAC, where positive (negative) $\mathrm{Z}$ components are indicating downward (upward) FAC (e.g. Kauristie et al., 2000). We conclude this section by using the quantitative time series results of the FAC related to our omega band event as an exemplary case to test this proxy. Figure 12 shows the $\mathrm{Z}$ component at the magnetometer station KIL (see Fig. 1; scale on the left side of the graph), together with the FAC just above that station, as determined from the method of characteristics (see Fig. 6c; scale on the right side of the graph). The large trend of the two curves follows each other fairly well, except for the beginning of the analysis period (03:18-03:19 UT). However, no simple linear relation can be established between the two quantities, and a shift of one minute exists between the minimum of $\mathrm{Z}$ and the most intense upward FAC over KIL. As KIL is located poleward of the center of the background westward electrojet, a positive offset in $\mathrm{Z}$ exists which causes this magnetic disturbance component to be positive throughout the interval under study. We conclude that for this event, the proxy of $Z$ is useful to roughly predict the zonal location of the strongest upward FAC, but any quantitative estimates would be subject to unpredictable errors.

Finally, Fig. 13 schematically summarises the behaviour of the substorm westward electrojet in the presence of omega bands, as inferred from this study. Instead of meandering along with the poleward boundary of the omega band tongues (left panel), as one could imagine from the structure of the equivalent currents (Fig. 3), a large part of the substorm electrojet is intermittently interrupted by alternating sheets of upward and downward currents, located at the western and eastern flanks of the omega bands' tongues, respectively. Only at the base of the omega bands, is a continuous westward electrojet present. 

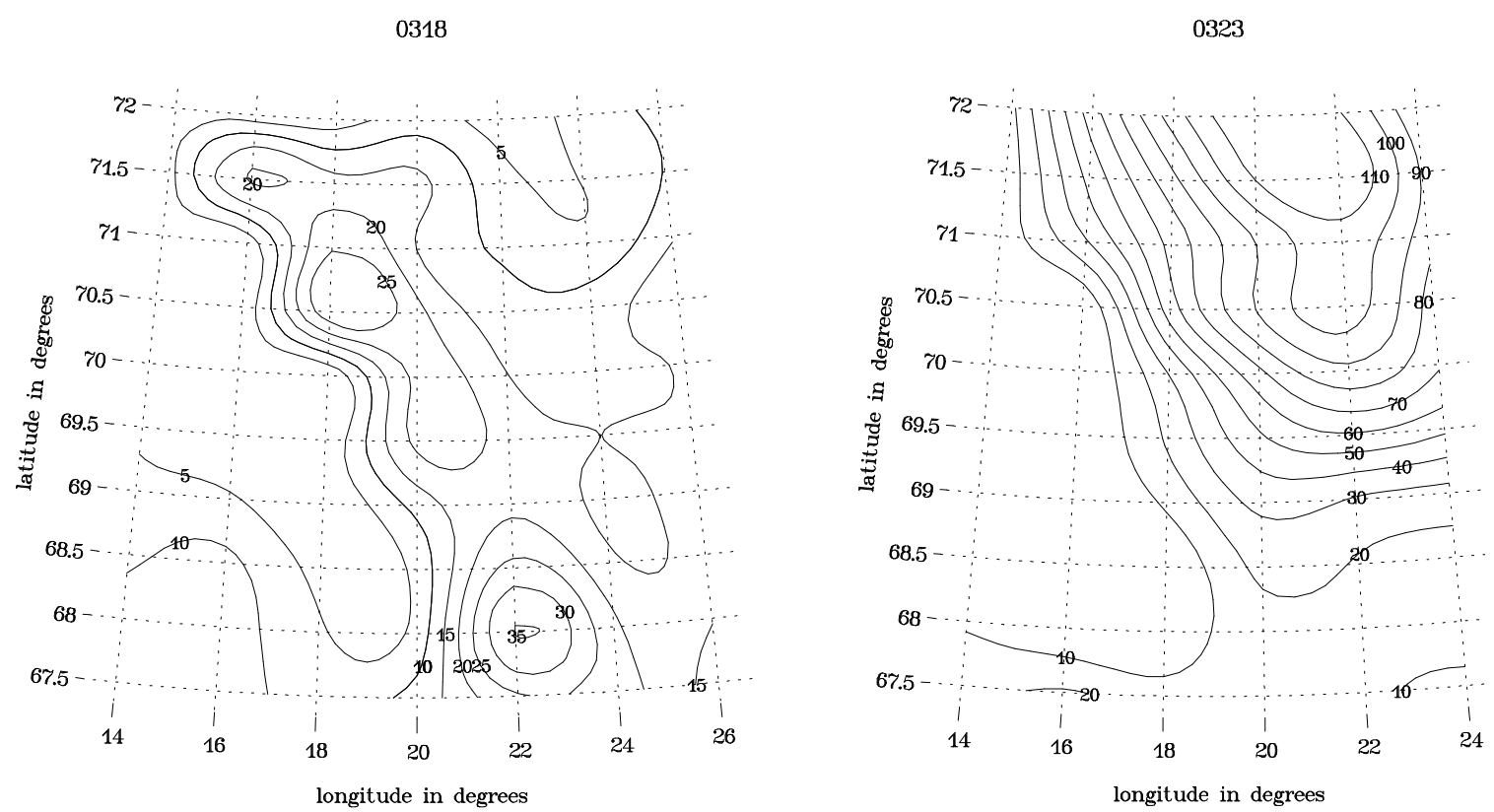

Fig. 11. Joule heating distributions (in $\mathrm{mW} \mathrm{m}^{-2}$ ) for two example time steps at 03:18 UT and 03:23 UT.

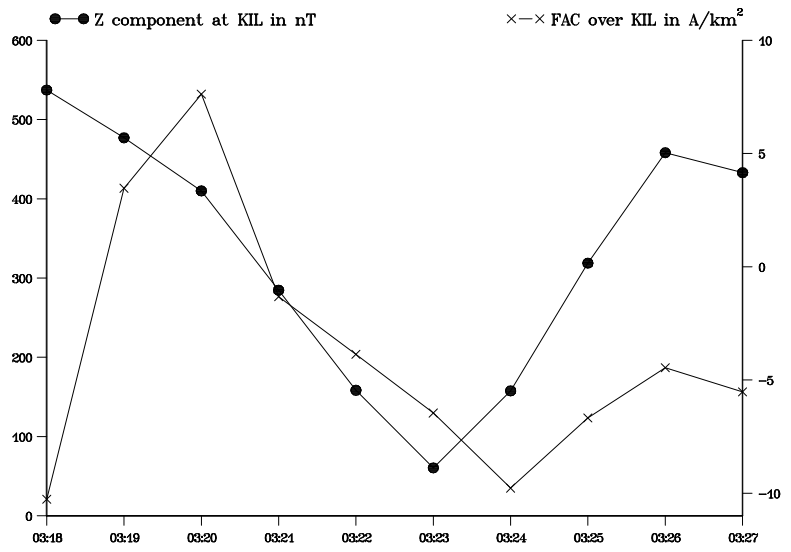

Fig. 12. Comparison of the $\mathrm{Z}$ magnetic disturbance component at KIL (dots, scale on the left side of graph), and the FAC density directly above KIL as inferred from the results of the method of characteristics (crosses, scale on the right side of the graph).

\section{Summary and conclusions}

In this study, we have presented electric and magnetic observations from the ground-based MIRACLE and BEAR networks and optical observations from the Polar satellite of an omega band event over Northern Scandinavia on 26 June 1998 , with a special focus on one omega band period from 03:18-03:27 UT. We have analysed these data using the 2D method of characteristics, in combination with a method to derive ionospheric conductances from the UVI and PIXIE data from the Polar satellite, which was used here to estimate the Hall-to Pedersen conductance ratio. The results of this direct and solely data-based analysis allow us, for the first time to fully resolve the spatio-temporal evolution of an omega

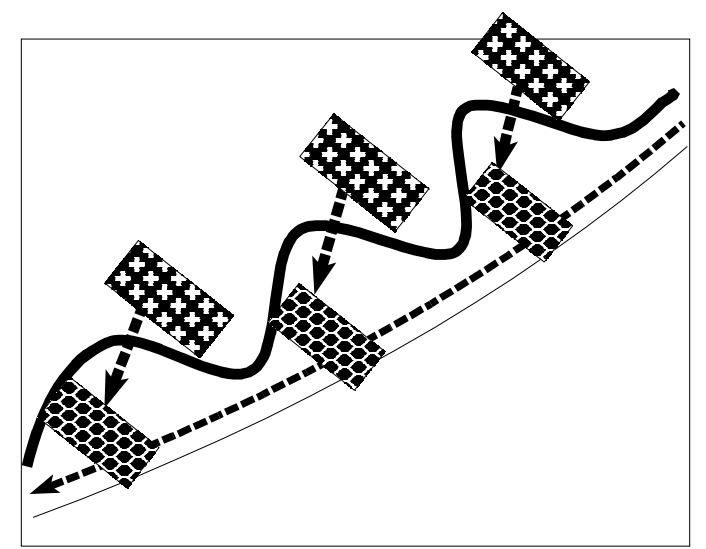

Fig. 13. Schematic sketch of the resulting geometry of the substorm electrojet current in the presence of omega bands. Areas with crosses denote downward FAC, and areas with circular patterns upward FAC.

band over one full period with a 1-min time and $\sim 50-\mathrm{km}$ spatial resolution. In addition, the AMIE method has been used to derive global Hall conductance patterns.

Our observations and analysis results can be summarized as follows:

1. The basic properties of the omega bands analysed here agree with the findings of earlier studies. A meandering equivalent current structure moves eastward with a velocity of $\sim 770 \mathrm{~m} \mathrm{~s}^{-1}$, causing magnetic Ps6 pulsations on the ground with a period of $\sim 8 \mathrm{~min} 30 \mathrm{~s}$ during the studied interval which are most clearly seen in the $\mathrm{Y}$ and $\mathrm{Z}$ disturbance components. While no visual band optical observations are available, the UVI images show an eastward moving intensification which is approximately aligned with the westward 
flank of the region of anticlockwise vorticity of the equivalent currents.

2. Except for the equatorward base region of the omega band, regions of large (up to $\sim 60 \mathrm{~S}$ ) and low $(<5 \mathrm{~S}$ ) Hall conductance are zonally alternating. The enhanced conductance "tongues" extend $\sim 400 \mathrm{~km}$ polewards from the base of the omega bands and have a longitudinal extension of $\sim 380 \mathrm{~km}$. Steep conductance gradients are present at the zonal and poleward edges of these regions. The conductances in the base region are comparable to the ones in the tongues.

3. The current system of the omega bands can be decomposed into two parts: One part consists of divergence-free Hall currents circulating anticlockwise around the enhanced conductance tongues and of almost radial Pedersen currents which divert to upward FAC of $\sim 4 \mu \mathrm{A} \mathrm{m}^{-2}$ in the center of those tongues. This current system causes the characteristic ground magnetic signature and is equivalent to the one proposed by Gustafsson et al. (1981). Its sign reverses inside the regions of low conductance. The second part mostly consists of westward flowing curl-free Hall current wedges which divert into strong upward FAC of $\sim 15-25 \mu \mathrm{A} \mathrm{m}^{-2}$ at the western flanks of the conductance tongues. Their feeding downward FAC at the eastern flanks of the tongues show magnitudes around $\sim 10 \mu \mathrm{A} \mathrm{m}^{-2}$. These currents are magnetically invisible below the ionosphere. Both current parts mentioned are about equally strong with maximum current densities of $\sim 1200 \mathrm{~mA} \mathrm{~m}^{-1}$ and are superposed to the background westward electrojet currents.

4. For our event, an overwhelming part (e.g. $>85 \%$ at 03:23 UT) of the FAC is associated with gradients of the ionospheric conductances, while the remaining part associated with divergences of the electric field is small. Between $66-84 \%$ of the FAC is connected with ionospheric Hall currents and controlled by the gradients of the Hall conductance. The total absolute FAC varies between 1.5-2.3 MA and is comparable to the one associated with a westward traveling surge. As the upward and downward FAC are not balanced over one omega band period inside our analysis area, we conclude that part of the upward FAC has to be fed by downward FAC located poleward of this area. Thus, the closing currents in the ionosphere are not flowing solely in zonal direction, but have an (equatorward) meridional component.

5. While the structures associated with the omega band are moving coherently eastward, they are not strictly stationary.

6 . The Joule heating is strongest inside the enhanced conductance tongues, where it reaches up to $\sim 120 \mathrm{~mW} \mathrm{~m}^{-2}$.

7. The $\mathrm{Z}$ magnetic disturbance component on the ground can be used as a rough proxy to qualitatively locate the maximum of the upward FAC for our event, but no quantitative relation between the two parameters can be established.

In addition to the ionospheric point of view, the results of our study have an important impact on the investigation of the ionosphere-magnetosphere coupling of omega bands. In particular, our finding that zonally aligned wedges of westward flowing Hall currents exist colocated with the conductance tongues is significant in this respect. These wedges carry a substantial amount of the total westward current and cause zonally alternating FAC which carry integrated currents comparable to a WTS to and from the magnetosphere, and are thus dominating the total FAC pattern of the omega bands. Although this topic is beyond the scope of this paper, we remark that such a situation might be compatible with the suggestion by Jørgensen et al. (1999) of large-scale oscillations of the inner edge of the tail current sheet. It would thus be of strong scientific interest to conduct a study like the present one when a multi-satellite magnetospheric mission like Cluster is located in an appropriate conjugate location with the omega bands.

Acknowledgements. The work of O. Amm has been supported by the Academy of Finland. The work of A. Aksnes was supported by the Research Council of Norway (NFR). We would like to thank the BEAR working group (team leader: T. Korja) for the BEAR magnetometer data.

Topical Editor M. Lester thanks J. Wild and A. Aikio for their help in evaluating this paper.

\section{References}

Akasofu, S.-I. and Kimball, D. S.: The dynamics of the aurora, 1. Instabilities of the aurora, J. Atmos. Terr. Phys., 26, 205, 1964.

Akasofu, S.-I.: A study of auroral displays photographed from the DMSP-2 satellite and from the Alaska meridian chain of stations, Space Sci. Rev., 16, 617, 1974.

Aksnes, A., Stadsnes, J., Bjordal, J., Østgaard, N., Vondrak, R. R., Detrick, D. L., Rosenberg, T. J., Germany, G. A., and Chenette, D.: Instantaneous ionospheric global conductance maps during an isolated substorm, Ann. Geophys., 20, 1181-1191, 2002, SRef-ID: 1432-0576/ag/2002-20-1181.

Aksnes, A., Stadsnes, J., Lu, G., Østgaard, N., Vondrak, R. R., Detrick, D. L., Rosenberg, T. J., Germany, G. A., and Schulz, M.: Effects of energetic electrons on the electrodynamics in the ionosphere, Ann. Geophys., 22, 475-496, 2004,

SRef-ID: 1432-0576/ag/2004-22-475.

Aksnes, A., Amm, O., Stadsnes, J., Østgaard, N., Germany, G. A., Vondrak, R. R., and Sillanpää, I.: Ionospheric conductances derived from satellite measurements of auroral UV and X-ray emissions, and ground-based electromagnetic data: A comparison, Ann. Geophys., 23, 343-358, 2005,

SRef-ID: 1432-0576/ag/2005-23-343.

Amm, O.: Direct determination of the local ionospheric Hall conductance distribution from two-dimensional electric and magnetic field data: Application of the method using models of typical ionospheric electrodynamic situations, J. Geophys. Res., 100, $24173,1995$.

Amm, O.: Improved electrodynamic modeling of an omega band and analysis of its current system, J. Geophys. Res., 101, 2677, 1996.

Amm, O.: Method of characteristics in spherical geometry applied to a Harang discontinuity situation, Ann. Geophys., 16, 413-424, 1998,

SRef-ID: 1432-0576/ag/1998-16-413.

Amm, O. and Viljanen, A.: Ionospheric disturbance magnetic field continuation from the ground to the ionosphere using spherical elementary current systems, Earth, Planets and Space, 51, 431, 1999. 
André, D. and Baumjohann, W.: Joint two-dimensional observations of ground magnetic and ionospheric electric fields associated with auroral currents, 5 . Current system associated with eastward drifting omega bands, J. Geophys., 50, 194, 1982.

Buchert, S., Baumjohann, W., Haerendel, G., La Hoz, C., and Lühr, H.: Magnetometer and incoherent scatter observations of an intense Ps 6 pulsation event, J. Atmos. Terr. Phys., 50, 357, 1988.

Buchert, S., Haerendel, G., and Baumjohann, W.: A model for the electric fields and currents during a strong Ps 6 pulsation event, J. Geophys. Res., 95, 3733, 1990.

Evans, R. D.: The Atomic Nucleus, McGraw-Hill Book Company, New York, USA., 1955.

Folkestad, K., Hagfors, T., and Westerlund, S.: EISCAT: An updated description of technical characteristics, Radio Sci., 18, 867, 1983.

Foster, J. C., Holt, J. M., Musgrove, R. G., and Evans, D. S.: Ionospheric convection associated with discrete levels of particle precipitation, Geophys. Res. Lett., 13, 656, 1986.

Frey, H. U., Mende, S. B., Vo, H. B., Brittnacher, M., and Parks, G. K.: Conjugate observations of optical aurora with polar satellite and ground-based cameras, Adv. Space Res., 23, 1647, 1999.

Fujii, R., Nozawa, S., Buchert, S. C., and Brekke, A.: Energy coupling between the magnetosphere, ionosphere and thermosphere, Adv. Space Res., 25, 213, 1999.

Fukushima, N.: Generalized theorem for no ground magnetic effect of vertical currents connected with Pedersen currents in the uniform-conductivity ionosphere, Rep. Ionos. Space Res. Jap., 30, 35, 1976.

Fuller-Rowell, T. J. and Evans, D. S.: Height-integrated Pedersen and Hall conductivity patterns inferred from the TIROS-NOAA satellite data, J. Geophys. Res., 92, 7606, 1987.

Germany, G. A., Parks, G. K., Brittnacher, M., Cumnock, J., Lummerzheim, D., Spann, J. F., Chen, L., Richards, P. G., and Rich, F. J.: Remote determination of auroral energy characteristics during substorm activity, Geophys. Res. Lett., 24, 995, 1997.

Germany, G. A., Parks, G. K., Brittnacher, M., Spann, J. F., Cumnock, J., Lummerzheim, D., Rich, F. J., and Richards, P. G.: Energy characterization of a dynamic auroral event using GGS UVI images, in Geospace Mass and Energy Flow: Results from the International Solar-Terrestrial Physics Program, edited by: Horwitz, J. L., Gallagher, D. L., and Peterson, W. K., 143, AGU, 104, Washington, D.C., 1998a.

Germany, G. A., Spann, J. F., Parks, G. K., Brittnacher, M., Elsen, R., Chen, L., Lummerzheim, D., and Rees, M.: Auroral observations from the Polar Ultraviolet Imager (UVI), in Geospace Mass and Energy Flow: Results from the International SolarTerrestrial Physics Program, edited by: Horwitz, J. L., Gallagher, D. L., and Peterson, W. K., 149, AGU, 104, Washington, D.C., 1998b.

Gjerloev, J. and Hoffman, R.: Currents in auroral substorms, J. Geophys. Res., 107, doi:10.1029/2001JA000194, 2002.

Greenwald, R. A., Weiss, W., Nielsen, E., and Thomson, N. R.: STARE: A new radar auroral backscatter experiment in northern Scandinavia, Radio Sci., 13, 1021, 1978.

Gustafsson, G., Baumjohann, W., and Iversen, I.: Multi-method observations and modeling of the three-dimensional currents associates with a very strong Ps 6 event, J. Geophys., 49, 138, 1981.

Imhof, W. L., Spear, K. A., Hamilton, J. W., Higgins, B. R., Murphy, M. J., Pronko, J. G., Vondrak, R. R., McKenzie, D. L., Rice, C. J., Gorney, D. J., Roux, D. A., Williams, R. L., Stein, J. A., Bjordal, J., Stadsnes, J., Njoten, K., Rosenberg, T. J., Lutz, L., and Detrick, D. L.: The Polar Ionospheric X-ray Imaging Exper- iment (PIXIE), Space Sci. Rev., 71, 385, 1995.

Inhester, B., Untiedt, J., Segatz, M., and Kürschner, M.: Direct determination of the local ionospheric Hall conductance distribution from two-dimensional electric and magnetic field data, J. Geophys. Res., 97, 4073, 1992.

Janhunen, P. and Huuskonen, A.: A numerical ionospheremagnetosphere coupling model with variable conductivities, J. Geophys. Res., 98, 9519, 1993.

Jørgensen, A. M., Spence, H. E., Hughes, T. J., and McDiarmid, D.: A study of omega bands and Ps6 pulsations on the ground, at low altitude and at geostationary orbit, J. Geophys. Res., 104, 14705 , 1999.

Kauristie, K., Sergeev, V. A., Kubyshkina, M., Pulkkinen, T. I., Angelopoulos, V., Phan, T., Lin, R. P., and Slavin, J. A.: Ionospheric current signatures of transient plasma sheet flows, J. Geophys. Res., 105, $10677,2000$.

Kawasaki, K. and Rostoker, G.: Perturbation magnetic fields and current systems associated with eastward drifting auroral structures, J. Geophys. Res., 84, 1464, 1979.

Korja, T., Engels, M., Zhamaletdinov, A. A., Kovtun, A. A., Palshin, N. A., Smirnov, M. Yu., Tokarev, A. D., Asming, V. E., Vanyan, L. L., Vardaniants, I. L., and the BEAR Working Group: Crustal conductivity in Fennoscandia - a compilation of a database on crustal conductance in the Fennoscandian Shield, Earth Planets Space, 54, 535, 2002.

Küppers, F., Untiedt, J., Baumjohann, W., Lange, K., und Jones, A. G.: A two-dimensional magnetometer array for ground-based observations of auroral zone electric currents during the International Magnetospheric Study (IMS), J. Geophys., 46, 429, 1979.

Lu, G.: A synthetic view of the magnetospheric-ionospheric current system associated with substorms, in Magnetospheric Current Systems, AGU monograph, edited by: Ohtani, S., Fujii, R., Lysak, R. L., and Hesse, M., 199, 2000.

Lühr, H. and Schlegel, K.: Combined measurements of EISCAT and the EISCAT magnetometer cross to study bands, J. Geophys. Res., 99, 8951, 1994.

Mravlag, E., Scourfield, M. W. J., Walker, A. D. M., Stucliffe, P. R., and Nielsen, E.: Simultaneous observations of omega band related phenomena in both hemispheres, J. Atmos. Terr. Phys., $53,309,1991$

Opgenoorth, H. J., Oksman, J., Kaila, K. U., Nielsen, E., and Baumjohann, W.: Characteristics of eastward drifting omega bands in the morning sector of the auroral oval, J. Geophys. Res., 88, 9171, 1983a.

Opgenoorth, H. J., Pellinen, R. J., Baumjohann, W., Nielsen, E., Marklund, G., and Eliasson, L.: Three-dimensional current flow and particle precipitation in a westward traveling surge (observed during the Barium-GEOS rocket experiment), J. Geophys. Res., $88,3138,1983 b$.

Østgaard, N., Stadsnes, J., Bjordal, J., Germany, G. A., Vondrak, R. R., Parks, G. K., Cummer, S. A., Chenette, D. L., and Pronko, J. G.: Auroral electron distributions derived from combined UV and X-ray emissions, J. Geophys. Res., 106, $26081,2001$.

Østgaard, N., Stadsnes, J., Bjordal, J., Vondrak, R. R., Cummer, S. A., Chenette, D., Schulz, M., and Pronko, J.: Cause of the localized maximum of X-ray emission in the morning sector: A comparison with electron measurements, J. Geophys. Res., 105, 20869, 2000.

Paschmann, G., Haaland, S., and Treumann, R. (Eds.): Auroral Plasma Physics, Kluwer Academic Publishers, Dordrecht, The Netherlands, 2003.

Pulkkinen, A., Amm, O., Viljanen, A., and BEAR working group: 
Ionospheric equivalent current distributions determined with the method of spherical elementary current systems, J. Geophys. Res., 108(A2), 1053, doi:10.1029/2001JA005085, 2003.

Rees, M. H.: Auroral ionization and excitation by incident energetic electrons, Planet. Space Sci., 11, 1209, 1963.

Richmond, A. D. and Kamide, Y.: Mapping electrodynamic features of the high-latitude ionosphere from localized observations: Technique, J. Geophys. Res., 93, 5741, 1988.

Saito, T.: Long period irregular micropulsations, Pi 3, Space Sci. Rev., 21, 427, 1978.

Sillanpää, I.: One-dimensional method of characteristics to determine ionospheric conductances and currents, unpublished Graduate Thesis at the University of Helsinki, Helsinki, Finland, 2002.

Sofko, G. J., Greenwald, R., and Bristow, W.: Direct determination of large-scale magnetospheric field-aligned currents with SuperDARN, Geophys. Res. Lett., 22, 2041, 1995.

Syrjäsuo, M., Pulkkinen, T. I., Pellinen, R. J., Janhunen, P., Kauristie, K., Viljanen, A., Opgenoorth, H. J., Karlsson, P., Wallman, S., Eglitis, P., Amm, O., Nielsen, E., and Thomas, C.: Observations of substorm electrodynamics using the MIRACLE network, Proc. Fourth International Conference on Substorms (ICS4), Lake Hamana, Japan, March 9-13, 1998.
Torr, M. R., Torr, D. G., Zukic, M., Johnson, R. B., Ajello, J., Banks, P., Clark, K., Cole, K., Keffer, C., Parks, G., Tsurutani, B., and Spann, J.: A far ultaviolet imager for the international solar-terrestrial physics mission, Space Sci. Rev., 71, 329, 1995.

Untiedt, J. and Baumjohann, W.: Studies of polar current systems using the IMS Scandinavian magnetometer array, Space Sci. Rev., 63, 245, 1993.

Vondrak, R. R. and Baron, M. J.: Radar measurements of the latitudinal variation of auroral ionization, Radio Sci., 11, 939, 1976.

Vondrak, R. and Robinson, R.: Inference of high-latitude ionization and conductivity from AE-C measurements of auroral electron fluxes, J. Geophys. Res., 90, 7505, 1985.

Wild, J. A., Yeoman, T. K., Eglitis, P., and Opgenoorth, H. J.: Multiinstrument observations of the electric and magnetic field structure of omega bands, Ann. Geophys., 18, 99-110, 2000,

SRef-ID: 1432-0576/ag/2000-18-99.

Yamamoto, T., Makita, K., Ozaki, M., and Meng, C.-I.: A particle simulation of auroral omega bands and torch-like structures, J. Geomag. Geoelectr., 45, 619, 1993.

Yamamoto, T., Inoue, S., and Meng, C.-I.: Formation of auroral omega bands in the paired region 1 and region 2 field-aligned current system, J. Geophys. Res., 102, 2531, 1997. 